\title{
Experimental analysis of self-healing cement-based materials incorporating extruded cementitious hollow tubes
}

\author{
Alessandra Formia ${ }^{1}$, Sara Irico² ${ }^{2}$ Federica Bertola ${ }^{3}$, Fulvio Canonico ${ }^{3}$, Paola Antonaci ${ }^{4}$, Nicola Maria \\ Pugno ${ }^{5,6,7}$ and Jean-Marc Tulliani ${ }^{1}$ \\ ${ }^{1}$ Department of Applied Science and Technology, INSTM Reference Laboratory for Ceramics Engineering, Politecnico di \\ Torino, Torino, Italy \\ ${ }^{2}$ Department of Science and Technological Innovation, Universita` del Piemonte Orientale, Alessandria, Italy \\ ${ }^{3}$ Buzzi Unicem SpA, Casale Monferrato, Italy \\ ${ }^{4}$ Department of Structural, Geotechnical and Building Engineering, Politecnico di Torino, Torino, Italy \\ ${ }^{5}$ Laboratory of Bio-Inspired \& Graphene Nanomechanics, Department of Civil, Environmental and Mechanical \\ Engineering, University of Trento, Trento, Italy \\ ${ }^{6}$ Center for Materials and Microsystems, Fondazione Bruno Kessler, Povo, Italy \\ 7 School of Engineering \& Materials Science, Queen Mary University of London, London, UK
}

Corresponding author: Jean-Marc Tulliani, Department of Applied Science and Technology, INSTM Reference Laboratory for Ceramics Engineering, Politecnico di Torino, Corso Duca degli Abruzzi, 24 - 10129 Torino, Italy. Email: jeanmarc.tulliani@polito.it

\begin{abstract}
In this work, new advances concerning the feasibility of extruded cementitious hollow tubes as containing/releasing devices for healing agents and their potential scaling up are presented. Specifically, sodium silicate and potassium silicate were evaluated as healing agents in terms of their ability to diffuse through cracks and of their ability to restore the initial mechanical properties of mortars. Their effect was investigated also in combination with the use of a hydrophobic coating applied to the inner surface of some of the hollow tubes to enhance the release of the healing agents along the crack path. A colorant was added to the sodium/potassium silicate solutions to help highlighting the fracture area covered by the healing agents, thus allowing a qualitative evaluation of the effect of the hydrophobic coating. Finally, image analysis was performed to correlate the mechanical strength/stiffness recovery to the area covered by the healing agent, as well as to the position of the tubes within the samples. On the whole, satisfactory results were obtained as far as restoration of the mechanical properties is concerned: the best performance was displayed when using cementitious hollow tube containing sodium silicate, with maximum values of bending load and stiffness recovery for the system of more than $70 \%$ and $50 \%$, respectively.
\end{abstract}

\section{Keywords}

self-healing, concrete, extruded cementitious hollow tubes, crack repair

\section{Introduction}

Concrete is one of the most used construction material due to its high strength, low cost, and flexibility in design. However, it is susceptible to crack formation as a consequence of its limited tensile strength. Cracking can be caused by a number of factors including structural loading, plastic and drying shrinkage, as well as thermal effects. Crack formation reduces the performance and endangers the durability of concrete structures allowing aggressive liquids and gases to seep through the matrix, causing further damage to the cement paste and to the steel rebars. To minimize 
deterioration, regular inspections and maintenance are necessary and are usually carried out with human intervention. Therefore, inspections and maintenance represent a remarkable cost for private and public administrations (Joseph et al., 2010). To minimize these costs, improving the economical sustainability of the structures through the extension of their service life is one of the top issues for the construction industry. For all these reasons, in the last decades, researchers have focused their attention on self-healing properties of cementitious materials (Van Breugel, 2007; Van Tittelboom and De Belie, 2013).

The autogeneous healing of concrete is a well-known phenomenon: under certain circumstances, concrete is able to self-heal its own damage. Autogeneous healing can happen as a consequence of calcite precipitation into cracks due to water infiltration (Huang and Ye, 2012; Neville, 2002; Van Tittelboom et al., 2012). In any case, this process is slow, limited to small cracks $(0.1-0.4 \mathrm{~mm})$, and is highly dependent on water $\mathrm{pH}$ (Ramm and Biscoping, 1998). Finally, the availability of water is not a problem for underground structures, while for aboveground ones, it could be provided by internal reservoirs such as super-absorbent polymers (Lee et al., 2010; Snoek et al., 2014), encapsulated water with paraffin (Antonaci et al., 2013; Janssen, 2011), and nanoclays (Quian et al., 2010).

To improve the self-healing ability in terms of mechanical recovery and sealing of bigger cracks, the efficiency of several healing agents and multiple encapsulation technologies was evaluated in a number of studies (Joseph et al., 2010; Mihashi et al., 2001; Van Tittelboom and De Belie, 2013; Wu et al., 2012). In particular, crack-repairing technology via embedded capsules with healing agents is becoming a promising approach to preserve and improve the performances of smart cementitious materials. This technological approach is based on the principle that when a crack comes across a capsule, the capsule shell is broken and thus, the healing agent contained in it can be released into the crack, restoring the damage.

The effectiveness of the healing process is complex and related to all the components of the system and the matrix: the viscosity of the healing agent and its curing time, the width of the crack, the size of the capsules, and the permeability of the shell and its mechanical resistance during the mixing process are some of the multiple variables which concurrently influence the healing capability (Van Tittelboom and De Belie, 2013). The features of the healing agents proposed in literature are numerous, a main distinction being the number of components: mono- or multi-components.

The multi-component agents, such as epoxy resin (Joseph et al., 2007), methyl methacrylate (MMA, Van Tittelboom et al., 2011a), poly(urethane) (PU; Hillouin et al., 2015; Maes et al., 2014; Van Tittelboom et al., 2011a), poly(acrylate) (Li et al., 1998), were thoroughly investigated and good results in terms of mechanical recovery and sealing properties were achieved. This typology of healing agent guarantees more stability than the mono-component materials because they react later directly in situ. However, their limitation is the necessity of a blend between the two reagents in the correct ratio.

On the contrary, with mono-component agents, the problems related to the incomplete mixing of different components are avoided. In particular, cyanoacrylates (Joseph et al., 2007) or inorganic expansive agents such as calcium-sulfoaluminate (Lee and Ryou, 2014; Sisomphon et al., 2012) react to the presence of moisture and cure rapidly. Epoxy (Dry, 2000; Thao et al., 2009) and MMA (Van Tittelboom and De Belie, 2013) resins can cure also upon heating while sodium silicate solutions (Formia et al., 2015a, 2015b; Huang and Ye, 2011; Pelletier et al., 2011) react with the cementitious matrix.

Concerning the encapsulation technology, capsules with spherical or tubular shapes were proposed. In the case of spherical capsules, the diameters reported in the literature range from $5 \mathrm{~mm}$ to $5 \mathrm{~mm}$, while for cylindrical capsules the diameters range from 0.8 to $7.5 \mathrm{~mm}$ (Formia et al., 2015a, 2015b; Van Tittelboom and De Belie, 2013). Vascular systems obtained with tubes filled with healing agent and connected to an external reservoir were also studied (Joseph et al., 2007; Mihashi et al., 2000). 
This kind of technology may be very useful for repairing large size cracks or also for restoring repeated damage occurrences; however, its difficult implementation (due to the complex positioning of the vascular net during concrete casting) represents a crucial disadvantage. For this reason, the addition of capsules to concrete during the mix preparation is preferable if it does not affect the workability of the concrete. In this case, the shell of the devices should be strong enough to survive the mixing process and the impact with the aggregates should also be sufficiently brittle to be fractured upon crack formation occurring in the concrete matrix once hardened. At the same time, when capsules are broken, it is important that they should easily release the healing agent. A spherically shaped capsule provides a more controlled release of the healing agent upon the breakage and the concentration of stresses around empty capsules are reduced. However, cylindrical capsules are generally better anchored to the matrix. In any case, independently of the shape, the probability that the crack intercepts the capsules is lower than $100 \%$. As simulated in the studies of Zemskov et al. (2011), this chance is related to several parameters such as the crack width, the capsule dimensions, their diffusion, and disposition into the matrix. Considering the higher surface-to-volume ratio of cylindrical capsules, their probability of breakage upon crack formation in the concrete matrix is likely to be higher compared to the spherical devices.

Anyway, after the healing agent releases, either a tubular or a spherical tube remains in the structure. The influence of these defects on the mechanical strength should be considered, but no data are available so far.

Different materials and technologies were tested to produce the shell of the capsules. The spherical devices are generally made of poly(urea-formaldehyde) (PUF), melamine-formaldehyde (MF) resins (Van Tittelboom and De Belie, 2013), PU (Pelletier et al., 2011), silica gel, gelatin (Van Tittelboom and De Belie, 2013), and paraffin (Antonaci et al., 2013; Janssen, 2011).

Concerning the capsules with a cylindrical shape, hollow glass, ceramic, extruded plastic, and cement tubes were used. Glass tubes demonstrated their efficiency during the test performed at laboratory scale; however, this shell material is incompatible with the mixing process and onsite application (Maes et al., 2014; Thao et al., 2009; Van Tittelboom et al., 2011b). In the work of Hillouin et al. (2015), extruded plastic tubes made of polystyrene, poly(lactic) acid, and poly (methyl methacrylate) were proposed. They were able to survive the mixing process without any particular protection and to break up upon crack appearance without an external intervention; however, the durability of the selected healing agent (PU resin) inside the capsule was limited.

In a previous study (Formia et al., 2015b), the authors presented the effectiveness of cementitious hollow tubes (CHTs) produced with an extrusion process. The tubes (internal diameter $=7.5 \mathrm{~mm}$; external diameter $=10 \mathrm{~mm}$ ) showed a flexural strength comparable to cementitious mortar. Moreover, the ability of the hollow tubes to surviving the mixing process was verified. In this case, sodium silicate was used as the healing agent. The preliminary results of three-point bending tests performed on mortar specimens containing the above-mentioned $\mathrm{CHT}$ indicated that sodium silicate was effectively released by the tubes. A good strength and stiffness recovery were evidenced, even for large cracks of more than $1 \mathrm{~mm}$. Moreover, a remarkable additional self-healing effect was also observed when further increasing the crack opening after the first selfhealing process had taken place.

In the previous study just mentioned, the authors tried to give an answer to some of the open points which were presented in the literature even if further investigation is needed to validate the proposed system. This study is therefore necessary to investigate other features of the extruded CHTs in order to better understand their behavior and in view of a potential scale-up process.

At first, in this research, the influence of some constitutive parameters of the tubes, such as the effect of two different coatings on the diffusion of the healing agent into the crack was evaluated: indeed, these coatings were made of a hydrophobicizing/non-hydrophobicizing agent and were used to 
investigate the possibility that they could confer hydrophobic properties to the internal surface of the tubular capsule, in such a way to promote the release of the aqueous healing agent contained in it upon crack formation. Moreover, the use of sodium and potassium silicate as healing agents was examined.

Second, some aspects related to the feasibility of the system were investigated. In particular, the attention was focused on the influence of the tubes on the mechanical properties of cured concretes through compression and ring tests.

Finally, the hollow tubes filled with sodium and potassium silicate were used to produce cementitious mortar samples tested in three-point bending in order to evaluate the mechanical recovery after cracking. The healing agents were colored to evaluate their diffusion into the cracks and an image analysis was performed to correlate the results of the mechanical recovery to the fracture area covered by the healing agents after damage repair, as well as to the position of the tubes within the samples. In the next section "Outline of the research," a detailed description of the experiments performed in this study is given.

\section{Outline of the research}

Taking the results of Formia et al. (2015b) as a starting point, in this study, the feasibility and effectiveness of self-healing cement-based materials incorporating extruded CHTs were further investigated. Specifically, a preliminary verification of the system feasibility was conducted with respect to its ability not to significantly alter the mechanical properties, due to the presence of the hollow tubes. To fulfill this aim, compression tests were performed on concrete samples incorporating $\mathrm{CHT}$ with various orientations and the results were evaluated in comparison with a standard concrete having the same composition apart from the presence of the tubular capsules.

In addition, the ability of the CHT to be broken upon crack formation in hardened concretes was verified through ring tests: this was done in order to simulate a damage situation frequently occurring in full-scale structures (i.e. restrained shrinkage cracking), in view of a potential scale-up process of the proposed self-healing system. Details and results of this research parts are presented in section "Preliminary verifications."

The influence of some constitutive parameters of the $\mathrm{CHT}$ (i.e. the healing agent contained in them and the effect of a hydrophobic coating applied to their internal surface with the aim to promote the release of the healing agent upon crack formation) was experimentally investigated in order to improve the self-healing response in terms of mechanical strength and stiffness recovery after damage. To do so, prismatic specimens containing CHT with two different healing agents (sodium or potassium silicate) in the presence or in the absence of a specific coating applied to the capsule shell inner surface (a siloxanic hydrophobicizing agent in water solution) were subjected to threepoint bending tests in crack mouth opening control in successive times. At first, the test was performed to induce a controlled localized damage in the samples (i.e. a bending crack occurring in the mid-section) and also to estimate their initial (undamaged) bending strength and stiffness. Subsequently, after a given period of time necessary for the self-healing reactions to be manifested, the test was performed again to evaluate the recovery of mechanical performances with respect to the initial values.

Photographs of the specimen cross sections were taken after the final failure in order to detect the fracture area covered by the healing agents prior to solidification so that speculations could be made about possible correlations with the outcome of the hydrophobicizing agent and the final mechanical recovery. A colorant additive was employed to enhance the visual contrast, improving the detection of the healing agent diffusion area. Details on these experiments, as well as presentation and discussion of the main results achieved, are provided in section "Experimental analysis." 


\section{Preliminary verifications}

As anticipated in section "Outline of the research," the influence of the addition of CHT on concrete compressive strength and cracking susceptibility needed to be evaluated. To do so, compressive tests and ring tests were performed, as reported in the following.

\section{Compressive tests}

Compressive tests were carried out on cubic specimens with a side length of $10 \mathrm{~cm}$. They were made of selfcompacting concrete (SCC) using CEM type I 52.5 R supplied by Buzzi Unicem S.p.A and calcareous aggregates having different particle size distributions, as reported in Table 1. Three of them, with no CHT added, were used as a reference, while nine of them, each one incorporating four $\mathrm{CHT}$, were used to evaluate the influence of the presence of the $\mathrm{CHTs}$ on the concrete compressive strength.

The CHTs were produced according to the procedure reported in Formia et al. (2015b) and here recalled in section "CHTs: extrusion, coating, and sealing." In a precautionary perspective, they were not filled with any substance to avoid any possible positive contribution to the compressive strength and also to simulate the condition of empty capsules, consequent to the release of the healing agent after damage. As reported in section "CHTs: extrusion, coating, and sealing," the tubes were characterized by a diameter of $1 \mathrm{~cm}$ and a length of about $5 \mathrm{~cm}$ so that the volume of each element was approximately of $4 \mathrm{~cm} 3$.

The CHTs were placed manually in each specimen, in such a way to dispose them horizontally, vertically, and randomly distributed with respect to the load direction; a SCC mix design was preferred for this test, in order to avoid the vibration process of the concrete, thus assuring the right $\mathrm{CHT}$ orientation. The CHTs were added in a proportion of four tubes per liter, corresponding to a volume ratio with respect to concrete of about $1.6 \%$. More specifically, they were put in position according to the following procedure. For horizontal and vertical orientations, first a layer of SCC was poured in the mold, then one tube was put on the fresh concrete surface, with a random position on the surface itself; after that, a second layer of concrete was poured and a second tube was placed; and so on until filling completely the mold with concrete including four CHTs. When testing the resulting hardened cubic specimen in compression, the orientation of the cube in the loading frame of the testing machine was such that the $\mathrm{CHT}$ inside it was disposed either horizontally (i.e. perpendicularly to load direction) or vertically (i.e. parallel to load direction). As far the random orientation of the $\mathrm{CHT}$ is concerned, the procedure followed for specimen production was approximately the same: first, a layer of SCC was poured in the mold, and then one tube was inserted into the fresh concrete layer, with a random position and inclination with respect to the surface of the concrete. After that, a second layer of concrete was poured and a second tube was placed in a similar way; and so on again until filling completely the mold with fresh concrete including four randomly oriented $\mathrm{CHT}$.

The samples were cured for 28 days at $90 \%$ relative humidity $(\mathrm{RH})$ until they were tested for compressive strength by means of a compression press (MCC8 Controls). The results obtained are reported in Table 2 and highlight that the addition of empty $\mathrm{CHT}$ in a SCC in a proportion of $1.6 \%$ in volume does not significantly influence the compressive strength. A minor effect related to the orientation of the $\mathrm{CHT}$ with respect to the load direction was observed, as the samples with randomly dispersed $\mathrm{CHT}$ showed a small strength decrease on average; such a reduction can be ascribed to the fact that the tubular capsules in this case were incorporated during casting by pressing them into the fresh concrete mix in order to guarantee a random orientation in space and this could have contributed to worsen the interfacial properties between concrete matrix and CHT. However, this variation is less than $10 \%$ and can be regarded as negligible, as confirmed by the Standard UNI EN 196-1 Methods of testing cement-Part 1: Determination of strength. Moreover, neither slipping nor 
de-bonding of the tubes was observed at the end of the compressive tests, each tube being perfectly adherent to the concrete matrix even after final failure (Figure 1).

\section{Ring tests}

To assess the ability of CHT to be broken and release their content due to crack formation, consequent to a restrained shrinkage process, ring tests were performed in accordance with the ASTM Standard C1581-04: Standard Test Method for Determining Age at Cracking and Induced Tensile Stress Characteristics of Mortar and Concrete under Restrained Shrinkage. This standard suggests to use an instrumented steel ring (measuring $330 \mathrm{~mm}$ in outer diameter, $150 \mathrm{~mm}$ in height, and $13 \mathrm{~mm}$ in thickness) to partly restrain the shrinkage of an annular concrete specimen (with the same height as the steel ring and $38 \mathrm{~mm}$ thick), that is cast around the ring. Due to the drying shrinkage, this type of constraint gives rise to a radial pressure on the steel ring and induces tensile stresses in the concrete. Finally, the tensile stress is released upon crack formation in the concrete and this occurrence can be detected using proper strain measuring devices applied to the steel ring. The age at cracking and the rate of tensile stress development in the test specimen are indicators of the material's resistance to cracking under restrained shrinkage.

Following these indications, in the present setup, the constraint was generated at $20 \mathrm{C}$ and $60 \% \mathrm{RH}$ and was measured by strain gauges placed on the inner side of the steel ring. The concrete composition was the same as for the compressive tests described in the previous section (Table 1). A SCC was chosen in order to enhance the drying shrinkage and hence the tensile stresses in the sample. The mix was poured into a mold that contained a V-shape indentation, which was introduced in such a way to create a notch in the annular concrete specimen (Figure 2). In this way, it was possible to induce macro-crack formation in a known region of the specimen. Four equally spaced $\mathrm{CHT}$ were manually positioned in this region, perpendicularly to the notch (Figure 2). The following samples containing $\mathrm{CHT}$ were considered:

- SCC sample with CHT containing a sodium silicate solution (SCC_CHT_S);

- SCC sample with CHT containing an aqueous solution of a colorant, Rhodamine B (SCC_CHT_W), to highlight the diffusion of the liquid into the crack;

- Finally, a SCC sample without CHT was used as a reference (SCC_ref).

Figure 3 shows the results of the average strain measured at the inner surface of the restrained steel ring at early age. The strain values are shown after the beginning of the exposure to drying $(24 \mathrm{~h}$ after casting). The time of through cracking is captured by a sudden strain release. Comparing the reference sample (SCC_ref) and the sample containing CHT filled with sodium silicate (SCC_CHT_S), it is possible to affirm that both samples manifested macro-cracks substantially at the same time. The sample SCC_CHT_S displayed also an additional sudden strain release 4 days after the appearance of the first macro-crack, which was due to the formation of another macro-crack at the diametrically opposite side.

This result suggests that, as expected, the tubes as such were not able to counteract the restrained shrinkage macro-cracking phenomena, but they were broken $\mathrm{Fi}$ after the damage occurrence and a visual observation revealed a good release of the sodium silicate inside the crack path (Figure 2).

The sample with the CHT containing aqueous solution of Rhodamine B (SCC_CHT_W) displayed the occurrence of a macro-crack at a later age. Indeed, the time of through cracking detected by the strain release was delayed, which can be due to a higher degree of micro-cracking and damage accumulation in this sample.

The Rhodamine B highlighted the diffusion of the fluid into the macro-crack by means of a visual observation. In Figure 2(a) and (b), images of the macrocrack are reported: the rupture of two hollow tubes as a consequence of cracking is clearly visible from the colored spots at two different points 
along the crack. Figure 2(c) and (d) demonstrates that the liquid inside the tubes was spread out along the fracture surface with a radius of about $5 \mathrm{~cm}$.

This innovative use of the ring test is a useful method for detecting cracking in restrained ring concrete specimens containing tubes/capsules for self-healing. Indeed, it is fast and does not require any other mechanical load to evaluate the capability of the capsules to be broken upon crack occurrence in the concrete matrix. However, the repairing effect cannot be observed in this experimental setup due to the different time scales of the processes involved, the self-healing process being governed by the time for the chemical reactions to be substantially complete, while the strain release process upon restrained shrinkage macro-crack formation is instantaneous.

\section{Experimental analysis}

The experimental analysis presented in this section was aimed at investigating the influence of some constitutive parameters of the extruded CHTs upon the final self-healing response of a cementbased system incorporating them. As anticipated in section "Outline of the research," some hollow tubes filled with different healing agents and characterized by different internal coatings were used to produce cementitious mortar samples tested in three-point bending in order to evaluate the mechanical performance after damage and selfhealing processes. In the following, details of the materials, specimens, equipment, and tests used for this research part are reported and discussed, together with the main results achieved.

\section{Materials and specimens}

Healing agents. Two healing agents were considered:

- Sodium silicate solution (provided by Sigma Aldrich, Na2O 10.6 wt\%, SiO2 26.5 wt\%, and H2O $62.9 \mathrm{wt} \%$ ) was selected considering the good results achieved in previous study (Formia et al., $2015 b)$, its low viscosity and its good compatibility with cementitious materials.

- Potassium silicate solution (K2O $21 \mathrm{wt} \%$, SiO2 $23 \mathrm{wt} \%$, and H2O $55 \mathrm{wt} \%$ ) was prepared by adding amorphous silica nanopowder (Sigma Aldrich, $20 \mathrm{~nm}, 99.5 \%$ purity) to a clear potassium hydroxide solution (8M). The solution was kept under magnetic stirring for $24 \mathrm{~h}$ prior to use. The potassium silicate solution was here proposed as an innovative healing agent due to its affinity with the cement matrix and its lower viscosity respect to a sodium silicate solution.

In order to identify and quantify the diffusion of the healing agents along the cracks, the silicate solutions were colored: after preliminary tests to check the chemical compatibility of the colorant with the healing agent, Rhodamine B was added to the potassium silicate solution, while methylene blue (Sigma Aldrich) was added to the sodium silicate solution. Both the silicate solutions were stirred until complete dissolution of the coloring agent.

CHTs: extrusion, coating, and sealing. CHTs were obtained by extrusion of a specifically designed cement paste, in accordance with the materials and processes detailed in Formia et al. (2015b) and here recalled. An extruding device at low pressure composed of a screw extruder and replaceable dies was used to extrude the fresh cement paste. The die has a ring shape, with an external diameter of $10 \mathrm{~mm}$ and an internal hole of $7.5 \mathrm{~mm}$. The extruded cylinders were cut into tubes measuring about $5 \mathrm{~cm}$ in length so that the volume of each element was approximately of $4 \mathrm{~cm} 3$.

After extrusion, the hollow tubes were left in a moist environment for 7 days and later in air for complete curing as suggested in the literature for polymermodified cementitious mortars (Aggarwal et al., 2007). 
With regard to the mix design for the hollow tubes, a low amount of water was used and several compounds were added to the cement paste to reach a good workability (Lombois et al., 2006; Mu et al., 1999) as reported in the following:

- Portland cement (CEM I 52.5 R, Buzzi Unicem, Italy);

- Copolymer of ethyl acrylate and MMA (Primal B60A, Sinopia, Italy);

- Poly(ethylene glycol) (PEG, Sigma Aldrich, Italy); Plasticizer (Dynamon SP1, Mapei, Italy);

- Hydroxypropylmethylcellulose (HPMC, Sigma Aldrich, Italy);

- Calcium carbonate (AnalytiCals, Carlo Erba, Italy).

All the liquids (water, Primal, PEG, plasticizer) were mixed together with an overhead stirrer (Janke and Kunkel IKA, RW 20) while the cement was added progressively, as well as the calcium carbonate powder, at the end. The mix design for the extruded hollow tubes is detailed in Table 3 (Formia et al., 2015b).

To increase the healing agent lifetime and to improve the shock resistance of the tube shells, the outer and inner surfaces of the CHT were coated with two different materials. Sodium silicate was applied as a first layer by complete immersion of the tubes. Subsequently, the extremities were sealed with wax and the healing agent was injected with a syringe until refusal. Finally, poly(vinyl)ester (PVE) resin cured in the presence of $2 \%$ of metyl-ethyl ketone peroxide (provided by Industria Chimica Reggiana SpA, Italy) was applied only on the exterior surfaces. Before completion of the curing process, the tubes were rolled into sand to improve the adhesion between the hollow tubes and the fresh mortar in which they had to be placed.

To enhance the release of the healing agent along the crack, a hydrophobic coating (Idrosil-acqua, Sinopia, Italy; a siloxanic hydrophobicizing agent in water solution, Figure 4) was applied by immersion to the surfaces of some of the tubes, above the sodium silicate layer, while some other ones were left with no hydrophobicizing coating for the sake of comparison.

Self-healing system: mortar prisms with CHTs. Four series of mortar specimens were produced, to be subjected to three-point bending tests for the evaluation of the selfhealing response.

Each series was composed of four samples, all prismatic in shape, measuring $163434 \mathrm{~cm} 3$ and having a water-to-cement ratio of 0.5 and a cement-to-sand ratio of $1: 3$ by weight, in accordance with the standard UNI EN 196-1 Methods of testing cement-Part 1: Determination of strength. In each specimen, a CHT was incorporated by placing it manually approximately at the center of the prism during the concrete casting (Figure 5), resulting in a volume ratio of the cementitious tube to the mortar specimen of about $1.56 \%$. The four series differed from each other only in the type of Figu CHT included: the series referred to as MSI (specimens denoted as MSI-i, with $i=1 \mathrm{O}$ 4) contained a CHT filled with sodium silicate and coated with the hydrophobicizing agent; the series MSN (specimens denoted as MSN-i, with $\mathrm{i}=1 \mathrm{O} 4$ ) contained a CHT filled with sodium silicate with no hydrophobic coating; similarly, the series referred to as MKI (specimens denoted as MKI-i, with $\mathrm{i}=1$ $\mathrm{O} 4$ ) contained a CHT filled with potassium silicate and coated with the hydrophobicizing agent; finally, the series MKN (again, specimens denoted as MKN-i, with $\mathrm{i}=1 \mathrm{O} 4$ ) contained a CHT filled with potassium silicate with no hydrophobic coating.

All the samples were cured in a humid environment $(\mathrm{RH}=90 \%)$ for $24 \mathrm{~h}$, and then they were demolded and immersed in water for 6 days before testing. After curing, all the samples were notched with a U-shaped notch measuring approximately $4 \mathrm{~mm}$ in width and $4 \mathrm{~mm}$ in height. A $25 \mathrm{~mm}$ gap clip-on gauge was placed in correspondence of the notch so as to measure the displacement at gap level during subsequent three-point bending tests.

Two plain mortar specimens and two mortar specimens incorporating a hollow tube filled with sand were produced (and tested) in Formia et al. (2015b), following the same procedure presented here: their data were used in this study for the sake of comparison. These specimens were denoted as 
TQ-i (with $\mathrm{i}=1 \mathrm{O} 2$ ) and MI-i (with $\mathrm{i}=1 \mathrm{O}$ 2), respectively, for the plain mortar series and for the series of mortar with $\mathrm{CHT}$ filled with sand.

\section{Experiments}

Tests for the characterization of the healing agents. Mechanical tests were performed to evaluate sodium silicate and potassium silicate as healing agents, considering that little information is available in the literature about this specific use.

Cementitious pastes (CEM I 52.5 R, Buzzi Unicem) having a water-to-cement ratio of 0.4 and containing $1 \%$ of plasticizer (Dynamon SP1, Mapei) were produced and cast in Plexiglass

molds sizing $7.53232 \mathrm{~cm} 3$. The samples (six in total) were cured at room temperature for 2 days in a humid environment ( $\mathrm{RH} 90 \%$ ), and then they were de-molded and immersed in water for 5 days. Finally, they were kept in air in indoor environment for 1 week. After 14 days from casting, the flexural strength of the cementitious samples was measured in three-point bending, using an electromechanical testing system (MTS Insight $1 \mathrm{kN}$, produced by MTS Systems Corporation, USA).

After complete failure in bending, the selected healing agents (i.e. sodium and potassium silicates) were applied by brush on the fracture surface generated in the middle of the specimens (three specimens per type of healing agent). The two fragments of the original prism were then kept joined together with an adhesive tape for 7 days. Then, the tape was removed and the bending test was performed again on the assembly thus obtained to evaluate the effectiveness of sodium silicate and potassium silicate as repairing agents. Depending on their capacity to create a stable link between the crack surfaces and to restore (part of) the original flexural strength of the element, the tested materials could be judged suitable to be used as a healing agent for concrete applications or not.

Tests for the characterization of the CHTs. A morphological characterization was carried out by means of a Field Emission-Scanning Electron Microscope (FE-SEM, Zeiss Merlin, Germany). FESEM observations were performed on the inner and outer surface of the hollow tubes to evaluate the features of the produced cementitious shells and to evaluate the homogeneity of the applied coatings. All the tubes were at least 1 -week old before the observations. The sodium silicate and the hydrophobic coating were applied directly on fragments of the hollow tubes to avoid the cracking of the coatings during the breakage of the tube. Both coating layers were cured 1 week before the observations.

Tests for the evaluation of the self-healing effect. To evaluate the self-healing potential of the proposed systems and to highlight the differences due to the constitutive parameters of the CHTs here explored, three-point bending tests were performed on the prisms belonging to the series MSI, MSN, MKI, and MKN described in section "Self-healing system: mortar prisms with CHTs."

The specimens were first subjected to a pre-loading in three-point bending using a $25 \mathrm{kN}$ closedloop servocontrolled MTS hydraulic press in crack mouth opening displacement (CMOD) control mode (Figure 6) in such a way to produce a localized crack in the mid-section. Then, they were unloaded when the crack opening reached a value of approximately $800 \mathrm{~mm}$, regardless of the residual load. The crack was maintained open for $5 \mathrm{~min}$ at the maximum opening before unloading. After that, the specimens were removed from the loading frame and always stored in a moist environment ( $\mathrm{RH} 90 \%)$ for 2 days on a two-point supporting device with the same span as that used for testing. Then, they were kept in indoor environment at room conditions for 6 months using the same supporting device. This was done in such a way that the self-healing reactions could be established and the potential differences in selfhealing times, due to different healing agents, could be omitted. At the end, all the specimens were tested again in three-point bending to evaluate their 
possible performance recovery: they were subjected to a re-loading stage with the same CMOD rate as in the pre-loading stage, up to failure.

As in the previous work of Formia et al. (2015b), large CMOD values were set in this study because it was focused on those damage states in concrete structures that could sensibly impair their functioning or durability. Based on the indications reported in the European standard EN 1992-1-1: Eurocode 2: Design of concrete structures-Part 1-1: General rules and rules for buildings, the CMOD value of $400 \mathrm{~mm}$ can be regarded as a threshold discriminating between an acceptable crack width in the serviceability limit state (cracks smaller than this do not need a specific control in a variety of structures and exposure classes) and an unacceptable crack width (that require crack control). Therefore, the attention was focused on CMOD values that were deliberately set much higher than $400 \mathrm{~mm}$ (i.e. approximately $800 \mathrm{~mm}$ ) just to emphasize this aspect, also considering that the extruded macro-tube system could be easily combined with other established selfhealing approaches that efficiently deal with smaller crack widths.

The self-healing effect was evaluated after each reloading stage through some performance recovery indices, by analogy with a common approach reported in the literature (Homma et al., 2009). In particular, a load recovery index (LRI) was defined as

$$
\operatorname{LRI}(\%)=\left(\frac{P_{r}-P_{u}}{P_{p}-P_{u}}\right) \times 100
$$

where $\mathrm{Pr}$ is the peak load obtained during the reloading stage, $\mathrm{Pp}$ is the peak load reached during the pre-loading stage (i.e. during crack creation in the intact material, corresponding to the material maximum strength), and $\mathrm{Pu}$ is the residual load obtained at the moment of unloading preceding the re-loading stage.

In addition, a stiffness recovery index (SRI) was calculated as

$$
\operatorname{SRI}(\%)=\left(\frac{S_{r}}{S_{p}}\right) \times 100
$$

where again $\mathrm{Sr}$ is the stiffness of the specimen during the re-loading stage and $\mathrm{Sp}$ is the stiffness of the intact specimen (i.e. the stiffness recorded in the pre-loading stage, prior to crack creation). In all cases, the stiffness was defined as the slope of the least-square linear fitting curve of the portion of the load versus CMOD data between $7.5 \%$ and $75 \%$ of the corresponding peak load. Please note that in the experimental setup here adopted, the values of the SRI defined in equation (2) are normally very close to zero if no healing occurs, even if the specimen is not completely broken during the initial loading stage. This is because the large CMOD values set cause a noticeable propagation of the crack along the specimen cross section and an eventual residual load $\mathrm{Pu}$ at the end of the initial loading stage, that is, nearly zero. For this reason, it was decided to calculate the stiffness recovery according to equation (2) instead of using an expression similar to equation (1) since in this case it should be required to reload the samples up to Pu immediately at the end of the initial preloading/un-loading stage (before a possible healing process could take place) in order to calculate the residual stiffness. As a matter of fact, this would be particularly hard from an experimental point of view (because $\mathrm{Pu}$ is very low and the experiment shall be conducted in CMOD control) so that there would be a serious risk to cause an additional, undesired, and uncontrolled damage to the specimen.

Please also note that some effects due to time (or rather to cement hydration) can play a role, since in these experiments the pre-loading process was carried out at an early age, namely when the cement hydration reactions were not completed. In this case, it is possible to adopt a correction for the LRI and SRI, in order to provide an estimation of the same indices as if they were obtained for pre-loading at the standard age of 28 days. Indeed, it is reasonable to assume that the contribution 
due to self-healing, that makes $\mathrm{Pr}$ rise with respect to $\mathrm{Pu}$, does not depend on cement hydration but rather on the characteristics of the healing agent and on its diffusion on the crack surface. Therefore, the gap between $\mathrm{Pr}$ and $\mathrm{Pu}$ can be regarded as independent of time and it can be calculated for early-age pre-loading. Conversely, the values of the peak load Pp obtained during the pre-loading stage would be higher if the specimens were tested at a later age and the same goes also for the residual load $\mathrm{Pu}$ so that a scaling factor $\mathrm{b}(\mathrm{t})$ can be introduced to estimate the values of $\mathrm{Pp}$ and $\mathrm{Pu}$ as if they were obtained at the age of 28 days, based on the values experimentally detected for preloading at an early age of $t$ days. As a consequence, an "actualized load recovery index" (ALRI) can be defined using the same scaling factor in this way

$$
\mathrm{ALRI}=\beta(t) \times \mathrm{LRI}
$$

where $A L R I$ is the estimated value of the LRI that would have been obtained if the pre-loading was performed at the age of 28 days; $L R I$ is the LRI calculated for pre-loading at an early age $t$, and $b(t)$ is the scaling factor. Such a scaling factor is the same that correlates the early-age strength of concrete $\mathrm{fcm}(\mathrm{t})$ to the asymptotic strength $\mathrm{fcm}$. According to Eurocode 2, its expression as a function of time is as follows

$$
\beta(t)=\frac{f_{c m}(t)}{f_{c m}}=\exp \left\{s\left(1-\sqrt{\frac{28}{t}}\right)\right\}
$$

with s coefficient that depends on the type of cement, that Eurocode 2 sets to 0.2 for CEM I 52.5 R, as the one used in this study.

As a result, it is found that $b=0.82$ for these experiments. Identical considerations apply to the definition of the SRI reported in equation (2) so that an "actualized stiffness recovery index" (ASRI) can be defined to account for time-dependent effects according to the following expression

$$
\mathrm{ASRI}=\beta(t) \times \mathrm{SRI}
$$

where again ASRI is the estimated value of the SRI that would have been obtained if the pre-loading was performed at the age of 28 days; $S R I$ is the SRI calculated for pre-loading at an early age $t$, and $b(t)$ is the same scaling factor as in equation (4).

A digital image of all the samples containing the tubes with the silicate solutions after complete failure was acquired by means of a digital camera (Nikon D70, Nikon Corp., Japan) and after that the images were processed with DxO Optics Pro 6.5.5 (DxO Labs, France) for optical corrections, specifically, distortion, chromatic aberrations, lens softness, and fine detail enhancement. Subsequently, Photoshop CS (Adobe Systems Inc., USA) was used to emphasize the colored areas. Finally, image analysis (Image-Pro Plus 4.0, MediaCybernetics Inc., USA) was performed on the processed images to determine the area covered by the healing agents spreading into the crack upon damage occurrence, the position of the tube with respect to the notch, the average diameter (the average value of diameters measured at 2 intervals and passing through object's centroid), and the aspect of the tube (defined as the ratio between major axis and minor axis of an ellipse equivalent to the measured object).

\section{Results and discussion}

Characterization of the healing agents. The tests performed on the reassembled samples described in section "Tests for the characterization of the healing agents" revealed that a surprising recovery of the flexural strength was obtained with the selected healing agents. In fact, all the samples reassembled with sodium silicate displayed a higher bending strength than the intact specimens, nearly double on average (Figure 7). On the contrary, the samples reassembled using 
the potassium silicate solution reached only slightly more than $20 \%$ of the bending strength of the intact specimens. These different behaviors could be ascribed to its lower viscosity: it is possible that the inorganic resin was partially absorbed into the matrix decreasing the amount of the liquid available for crack filling and repairing.

Characterization of the CHTs. As anticipated in section "Tests for the characterization of the CHTs," FE-SEM observations were conducted on the CHTs produced for this study. These observations (Figure 8(a)) showed that the interior surface of the hollow tubes was homogeneous, and that the added calcium carbonate appeared to be well dispersed into the cementitious matrix. Moreover, the polymer seemed to be uniformly distributed on the surface. A homogeneous deposition of the amorphous silica film is visible (Figure 8(b)). A FE-SEM micrograph of the hydrophobic film applied on the internal sodium silicate coating is also reported in Figure 9: this film seems to be rather homogeneous and well distributed onto the treated surface.

Evaluation of the self-healing effect. The results of the three-point bending tests performed for the evaluation of the self-healing effect are reported in Figures 10 to 14 and in Figures 15 and 16, respectively, in terms of load versus CMOD curves and in terms of average LRI and SRI-both for early-age pre-loading and actualized, in accordance with equations (1), (2), (3), and (5). From these graphs, it is immediately evident that the proposed self-healing system as a whole is definitely effective. Indeed, the control specimens presented LRIs that ranged approximately from $+0.9 \%$ to $+2 \%$ (correspondingly, the ALRIs ranged from $0.7 \%$ to $1.6 \%$ ) and SRIs (either actualized or not) that never exceeded $+0.1 \%$. Such a (reduced) self-healing effect has to be ascribed to the wellknown phenomenon of further hydration of un-reacted cement particles and is deemed to be insufficient from a mechanical point of view, especially in terms of stiffness recovery. On the contrary, the specimens incorporating the $\mathrm{CHT}$ manifested in general a considerable restoration of the mechanical properties, with LRIs always largely positive, ranging from a minimum value of $+5.3 \%$ (samples MKN-1 and MKN-2) to an impressive $+70.9 \%$ (sample MSN- 4), and SRIs assuming the limit values of $+2.7 \%(\mathrm{MKN}-2)$ and $+53.6 \%(\mathrm{MSN}-4)$. These values are reduced to less than $20 \%$ when considering the actualized values of ALRI and ASRI in accordance with equations (3) and (5), which anyway do not alter the significance of the results. Such a high extent of performance recovery corroborates the results presented in Formia et al. (2015b) and appears to be even more remarkable considering that the crack-opening values reached during the damaging stage were imposed to be quite large, that is, equal to or larger than $800 \mathrm{~mm}$.

Exploring now the differences due to the constitutive parameters of the $\mathrm{CHT}$, it can be noted that in general, the mechanical results achieved using the potassium silicate as a healing agent are lower than the ones obtained with sodium silicate. This was expected based on the results of the preliminary characterization tests reported in section "Tests for the characterization of the healing agents": as a matter of fact, despite the low expectations, the specimens belonging to the MKI and MKN series offered a quite satisfactory self-healing behavior.

Surprisingly, no influence of the hydrophobic coating on the mechanical recovery was observed: this leads to the conclusion that either the hydrophobicizing agent here used was ineffective or, in general, the role of any hydrophobic coating is marginal with respect to the other physical phenomena governing the leakage of a liquid from a tubular capsule into an open crack (attractive and resistive capillary forces, gravity, negative pressure forces at the edges of the CHT, surface tensions at the meniscus of the leaking fluid, and so on).

To gain a further insight, several parameters were investigated for each sample: the area covered by the healing agent and the direction of propagation of the fluid, the distance between the tube and the notch, and the shape of the tube; all these data were correlated with the values of LRI and SRI. 
The data concerning the most representative samples are reported in Table 4. At first sight, it is possible to conclude that only one of the above-mentioned parameters is insufficient to determine the degree of recovery of mechanical properties.

Sample MSN-4 achieved the best LRI and SRI: a remarkable amount of healing agent was released from the tube and covered an area of $2.17 \mathrm{~cm} 2$ which was equivalent to $15 \%$ of the prism's surface. The tube was characterized by a regular shape (aspect $=1.2$ ) and it was positioned in the middle of the prism. The liquid spread out in the direction of the crack mouth, thus contributing to an effective reparation of the damaged cross section and eventually leading to higher LRI and SRI.

Samples MSN-2 and MSN-3 reached recovery indices lower than the MSN-4 sample but satisfactory anyway. In particular, in the sample MSN-3, the area covered by the fluid upon crack formation is lower than the data measured for the previous samples. It could be due to the higher distance between the tube and the notch. In fact, in this position, the crack is narrower and it could reduce the possibility for the liquid to spread out.

The mechanical results of the samples incorporating the tubes filled with sodium silicate and coated with the hydrophobic layer are homogeneous. For all these samples, the area covered by the fluid upon crack formation is around $12 \%$ of the total surface of the prism (in Table 4 only the data concerning the sample MSI-3 are reported for the sake of brevity and they could be used as representative of all the series $\mathrm{MSI}$ ). This is a considerable amount of liquid if compared with the samples MSN-3 and MSN-4 but, in this case, the healing agent flowed horizontally with a lower effect in terms of mechanical restoration.

Sample MKN-2 exhibited the least recovery. Several features contributed to this low mechanical recovery: the tube was positioned far from the notch, only a small amount of healing agent was released and its diffusion was limited by the proximity of the wall of the tube.

MKI-2 achieved the best result compared to the other samples of the MKI series with regard to both $\mathrm{LRI}$ and SRI. As a matter of fact, all the samples belonging to the MKI series reached comparable or higher LRI values but were significantly worse in terms of stiffness recovery. In the sample MKI2 , the tube was situated in the middle of the sample and a notable amount of healing agent wetted the prism surfaces. However, the fluid diffused horizontally giving, in this way, a reduced contribution to the mechanical properties recovery.

To summarize, it is possible to state that to achieve a good mechanical recovery, it is necessary that the tubes have a regular shape and they should be placed close to the crack mouth to facilitate the diffusion of the fluid. Moreover, it seems that if the healing agent is able to diffuse backward with respect to the direction of propagation of the crack, the mechanical recovery indices are higher. Then, when re-loading the sample, crack initiation and propagation will be much more difficult because the original crack, where tensile stresses are maximum, has been sealed.

\section{Conclusion}

In this work, CHTs obtained by an extrusion process were successfully produced and characterized as an innovative fluid-containing/delivering system for selfhealing concrete applications. A cement mix composition for the CHT was carefully selected in order to control the extrusion process parameters. Sodium silicate and potassium silicate were used as the healing agents to be encapsulated into the extruded CHTs. The effect of the presence of the CHT on the inherent mechanical properties of a concrete was investigated to check the feasibility of the proposed system for self-healing concrete applications. The characteristics of the CHT shells and coatings were examined using a multifaceted approach in order to characterize their ability to be broken upon crack formation, their liquid-storage capability, and their effectiveness in releasing their liquid healing agent content into an open crack in the cementitious matrix. The actual self-healing effect of the proposed 
system was evaluated in terms of mechanical recovery after damage as induced by three-point bending tests in cementitious mortars.

The main conclusions achieved are the following:

1. The influence of the presence of CHTs on the inherent mechanical strength of concrete was evaluated through compressive tests carried out on a reference SCC and on a SCC incorporating 1.6 vol\% of $\mathrm{CHT}$. The results showed that the compressive strength is not significantly influenced by the presence of the hollow tubes, independently of their orientation with respect to the load direction. Such a result corroborates the feasibility of a self-healing system based on the use of extruded CHTs for structural concrete applications.

2. A ring test setup was proposed as an innovative method to evaluate the ability of the CHTs to be broken due to crack formation, as induced by restrained shrinkage. The results of the ring tests showed that the $\mathrm{CHT}$ were broken as a consequence of micro- and macro-cracking occurring in concrete due to drying shrinkage and the liquid diffusion was observed almost all through the sample width (diffusion radius of $5 \mathrm{~cm}$ ), demonstrating the effectiveness of the proposed solution in terms of capability of the tubular capsule shells to be broken and to release their liquid content as a consequence of damage occurrence in the cementitious matrix.

3. A three-point bending test setup was proposed to induce a controlled damage and to evaluate quantitatively the self-healing effect on cementitious samples at laboratory conditions. The results highlighted the effectiveness of the system in terms of recovery of stiffness and loadcarrying capacity, especially when using sodium silicate as a healing agent rather than potassium silicate. In particular, the maximum values of LRI and SRI were slightly more than $70 \%$ and $50 \%$, respectively, and they were achieved using sodium silicate as a healing agent.

4. Image analysis was performed to correlate the recovery of bending load and stiffness to the area covered by the diffusion of the healing agent upon crack formation, as well as to the position of the tubes within the samples. The results highlighted that a direct correlation between these parameters and the mechanical recovery cannot be found. However, it appears that if the healing agent is able to move backward with respect to the direction of propagation of the crack, the mechanical recovery turns out to be higher.

5. The use of a hydrophobic coating on the inner surface of some tubes to enhance the release of the healing agents along the cracks was also evaluated, but it seemed to have no substantial influence on the size of the area covered by the fluid diffusion upon crack formation and on the mechanical recovery. This unexpected result has to be ascribed to the possible ineffectiveness of the hydrophobicizing agent here used. Otherwise, it has to concluded that, in general, the role of any hydrophobic coating is marginal with respect to the other physical phenomena governing the leakage of a liquid from a tubular capsule into an open crack, such as the attractive and resistive capillary forces, gravity, negative pressure forces at the edges of the $\mathrm{CHT}$, surface tensions at the meniscus of the leaking fluid, and so on.

6. On the whole, the proposed self-healing system based on the use of cylindrical capsules made of extruded CHTs and filled with a silicate solution appears to be very promising, although further research is still needed in view of its optimization.

\section{Acknowledgements}

P.A. and A.F. gratefully acknowledge the CRT Foundation/ ISI Foundation, respectively, for funding the SHeCrete Research Project in the frame of the call La Ricerca dei Talenti by Politecnico di Torino and for financing a Research Grant in the frame of the Lagrange Project. The following institutions and people are also acknowledged: Mapei S.p.A., Mr Stefano Broggio, for providing the 
superplasticizer; Industria Chimica Reggiana S.p.A., Mr Michele Marini, for providing polyester resin; Department of Structural, Geotechnical and Building Engineering of Politecnico di Torino, Mr Vincenzo Di Vasto, for supporting the mechanical tests.

\section{Declaration of Conflicting Interests}

The author(s) declared no potential conflicts of interest with respect to the research, authorship, and/or publication of this article.

\section{Funding}

The author(s) disclosed receipt of the following financial support for the research, authorship, and/or publication of this article: N.M.P. is supported by the European Research Council (ERC Starting Grant Ideas 2011 BIHSNAM No. 279985 on "Bio-inspired hierarchical supernanomaterials," ERC Proof of Concept (PoC) 2013-1 REPLICA2 No. 619448 on "Large-area replication of biological antiadhesive nanosurfaces," ERC PoC 2013-2 KNOTOUGH no. 632277 on "Super-tough knotted fibres"), by the European Commission under the Graphene Flagship (WP10 "Nanocomposites," No. 604391), and by the Provincia Autonoma di Trento ("Graphene nanocomposites," No. S116/2012242637 and regional deliberation No. 2266).

\section{References}

Aggarwal LK, Thapliyal PC and Karade SR (2007) Properties of polymer modified mortars using epoxy and acrylic emulsions. Construction and Building Materials 21: 379-383.

Antonaci P, Pugno NM and Tulliani JM (2013) Production and mechanical behavior of microencapsulated self-healing cement: a case study. In: 5th world tribology congress, Turin, 8-10 September.

Dry CM (2000) Three designs for the internal release of sealants, adhesive, and waterproofing chemicals into concrete to reduce permeability. Cement and Concrete Research 30: 1969-1977.

Formia A, Antonaci P, Irico S, et al. (2015a) Extruded cementitious hollow tubes: an innovative encapsulation technology for healing agents in concrete and mortars. In: International workshop on durability and sustainability of concrete structures, Bologna, 1-3 October.

Formia A, Terranova S, Antonaci P, et al. (2015b) Setup of extruded cementitious hollow tubes as containing/releasing devices in self-healing systems. Materials 8: 1897-1923.

Hillouin B, Van Tittelboom K, Gruyaert E, et al. (2015) Design of polymeric capsules for self-healing concrete. Cement and Concrete Composites 55: 298-307.

Homma D, Mihashi H and Nishiwaki T (2009) Self healing capability of fiber reinforced cementitious composites. Journal of Advanced Concrete Technology 7(2): 217-228.

Huang $\mathrm{H}$ and $\mathrm{Ye} \mathrm{G}$ (2011) Application of sodium silicate solutions as self healing agent in cementitious materials. In: International RILEM conference on advances in construction materials, Hong Kong, China, 5-7 September.

Huang $\mathrm{H}$ and $\mathrm{Ye} \mathrm{G}$ (2012) Simulation of self healing by further hydration in cementitious materials. Cement and Concrete Composites 34: 460-467. 
Janssen D (2011) Water encapsulation to initiate self-healing in cementitious materials. Master's Thesis, Delft University, Delft.

Joseph C, Gardner D, Jefferson T, et al. (2010) Self healing cementitious materials: a review of recent work. Construction Materials 164: 29-41.

Joseph C, Jefferson AD and Cantoni MB (2007) Issues relating to the autonomic healing of cementitious materials. In: Proceedings of the first international conference on self healing materials, Noordwijk, 18-20 April.

Lee HDX, Wong HS and Buenfeld NR (2010) Potential of superabsorbent polymers for self-sealing cracks in concrete. Advances in Applied Ceramics 109: 296-302.

Lee Y-S and Ryou J-S (2014) Self healing behavior for crack closing of expansive agent via granulation/film coating method. Construction and Building Materials 71: 188-193.

Li VC, Lim YM and Chan Y-W (1998) Feasibility study of a passive smart self-healing cementitious composite. Composites Part B: Engineering 29(6): 819-827.

Lombois-Burger H, Colombet P, Halary JL, et al. (2006) Kneading and extrusion of dense polymercement paste. Cement and Concrete Research 36: 2086-2097. Maes M, Van Tittelboom K and De Belie N (2014) The efficiency of self healing cementitious materials by means of encapsulated polyurethane in chloride containing environments. Construction and Building Materials 71: 528-537.

Mihashi H, Kaneko Y, Nishiwaki T, et al. (2000) Fundamental study on development of intelligent concrete characterized by self-healing capability for strength. Transactions of the Japan Concrete Institute 22: 441-450.

Mihashi H, Kaneko Y, Nishiwaki T, et al. (2001) Fundamental study on development of intelligent concrete characterized by self healing capability for strength. Transaction of the Japan Concrete Institute 22(2): 441-450.

Mu B, Li Z, Chui SNC, et al. (1999) Cementitious composite manufactured by extrusion technique. Cement and Concrete Research 26: 237-240. Neville A (2002) Autogenous healing-a concrete miracle? Concrete International 24(11): 76-82.

Pelletier M, Brown R, Shkula A, et al. (2011) Self healing concrete with a microencapsulated healing agent. Available at: http://energetics.chm.uri.edu/system/files/Self\%20- healing\%20concrete\%20-711.pdf (accessed 5 September 2013).

Quian SZ, Zhou J and Schlangen E (2010) Influence of curing condition and precracking time on the self-healing behavior of engineered cementitious composites. Cement and Concrete Composites 32: 686-693.

Ramm W and Biscoping M (1998) Autogenous healing and reinforcement corrosion of waterpenetrated separation cracks in reinforced concrete. Nuclear Engineering and Design 179: 191-200.

Sisomphon K, Copuroglu O and Koenders EAB (2012) Selfhealing of surface cracks in mortars with expansive additive and crystalline additive. Cement and Concrete Research 34: 566-574.

Snoek D, Van Tittelboom K, Steuperaet S, et al. (2014) Self healing cementitious materials by combination of microfibers and superabsorbent polymers. Journal of Intelligent Material Systems and Structures 25(1): 13-24.

Thao TDP, Johnson TJS, Tong QS, et al. (2009) Implementation of self healing concrete-proof of concept. The IES Journal Part A: Civil and Structural Engineering 2(2): 116-125.

Van Breugel K (2007) Is there a market for self-healing cement-based materials? In: Proceedings of the first international conference on self healing materials, Noordwijk, 18-20 April. 
Van Tittelboom K, Adesanya K, Dubruel P, et al. (2011a) Methyl methacrylate as a healing agent for self-healing cementitious materials. Smart Materials and Structures 20: 125016.

Van Tittelboom K and De Belie N (2013) Self-healing in cementitious materials-a review. Materials 6: 2182-2217.

Van Tittelboom K, De Belie N, Van Loo D, et al. (2011b) Self healing efficiency of cementitious materials containing tubular capsules filled with healing agent. Cement and Concrete Composites 33: 497-505.

Van Tittelboom K, Gruyaert E, Rahier H, et al. (2012) Influence of mix composition on the extent of autogenous crack healing by continued hydration or calcium carbonate formation. Construction and Building Materials 37: 349-359.

Wu M, Johannesson B and Geiker M (2012) A review: selfhealing in cementitious materials and engineered cementitious composite as a self healing material. Construction and Building Materials 28: 571-583.

Zemskov SV, Jonkers HM and Vermolen FJ (2011) Two analytical models for the probability characteristics of a crack hitting encapsulated particles: application to self-healing materials. Computational Materials Science 50: 3323-3333. 
Table I. Concrete mix design for compression tests.

\begin{tabular}{ll}
\hline Compound & Amount $\left(\mathrm{kg} / \mathrm{m}^{3}\right)$ \\
\hline CEM I 52.5 R & 450 \\
Limestone powder $^{\mathrm{a}}$ & 150 \\
Aggr. < I mm & 553 \\
Aggr. I-4 mm & 235 \\
Aggr. 2-8 mm & 235 \\
Aggr. 4-8 mm & 235 \\
Aggr. 4-10 mm & 311 \\
Plasticizer & 10 \\
Water & 208 \\
\hline
\end{tabular}

Table 2. Compressive strength after 28 days of curing (average of three results).

\begin{tabular}{lll}
\hline Sample & $\begin{array}{l}\text { Compressive } \\
\text { strength (MPa) }\end{array}$ & $\begin{array}{l}\text { Variation with } \\
\text { respect to SCC } \\
\text { reference (\%) }\end{array}$ \\
\hline $\begin{array}{l}\text { SCC reference } \\
\text { SCC with horizontally }\end{array}$ & 36.55 & - \\
$\begin{array}{l}\text { oriented hollow tubes } \\
\text { SCC with vertically } \\
\text { oriented hollow tubes }\end{array}$ & 35.95 & -0.3 \\
$\begin{array}{l}\text { SCC with randomly } \\
\text { distributed hollow tubes }\end{array}$ & 33.45 & -1.6 \\
\hline
\end{tabular}




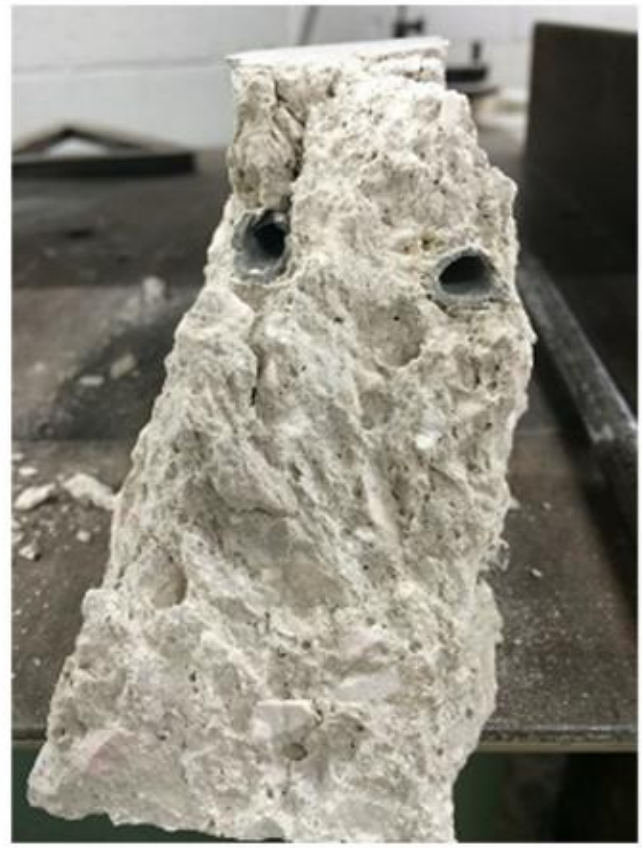

Figure I. Fragment of the cubic specimen with horizontally oriented hollow tubes after failure in compression: two fractured hollow tubes are visible at the top of the fragment and the good adhesion between the tubes and the cementitious matrix can be noted. 


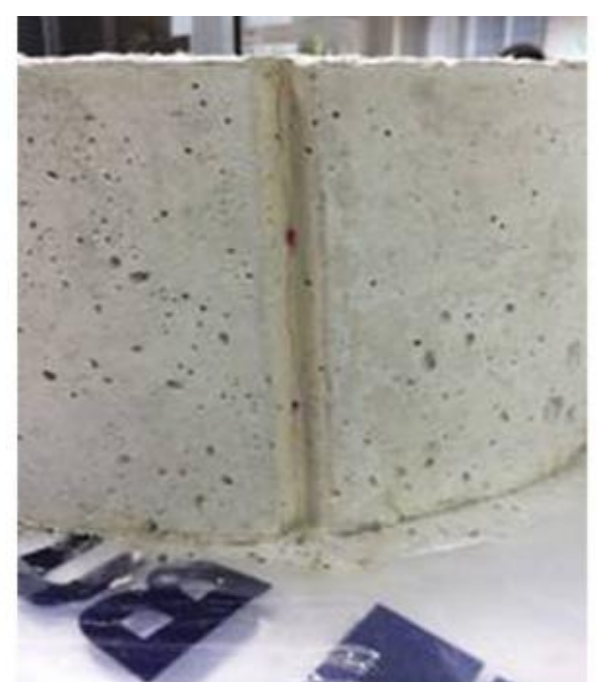

(a)

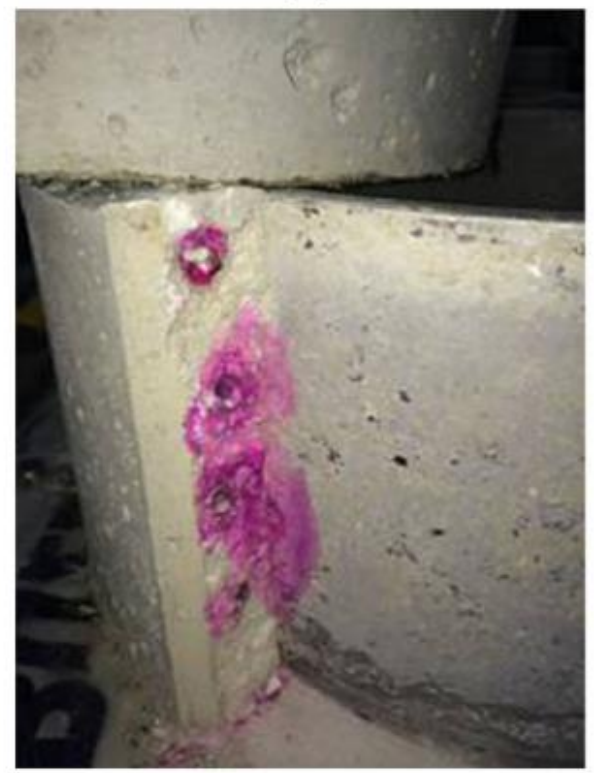

(c)

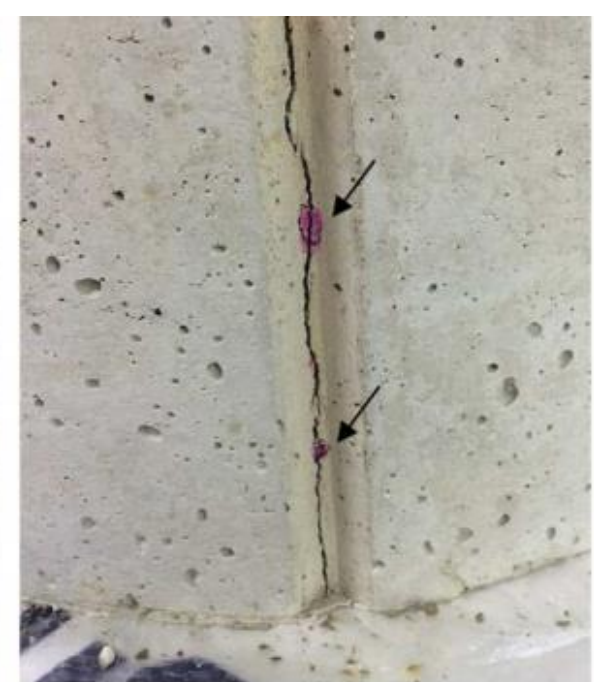

(b)

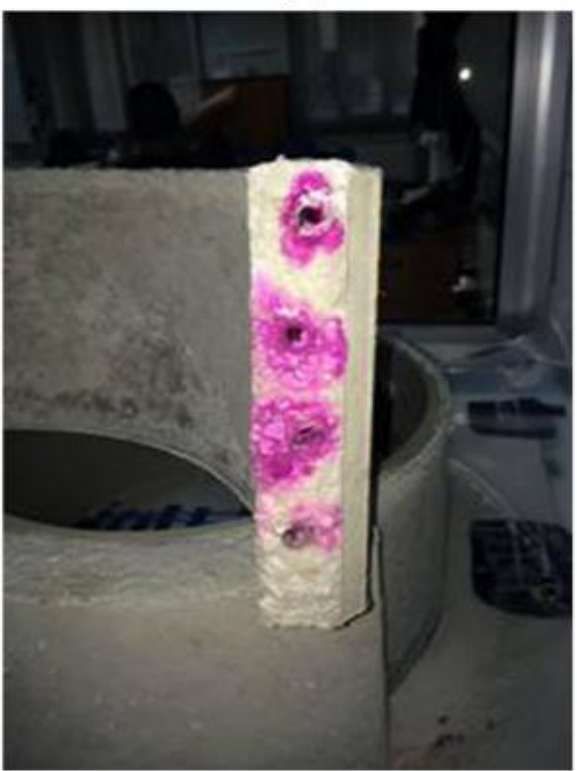

(d)

Figure 2. Ring tests images: (a) first micro-cracking leading to the diffusion of Rhodamine B water solution up to the external surface of the concrete annular specimen; (b) macro-cracking; (c) and (d) crack surfaces with Rhodamine-colored water diffusion around the hollow tubes.

Table 3. Composition of the cement paste for the extrusion of the $\mathrm{CHT}$ (proportion with respect to the cement).

\begin{tabular}{lllllll}
\hline Water/cement ratio (-) & Water (wt\%) & Primal (wt\%) & PEG (wt\%) & Superplasticizer (wt\%) & HPMC (wt\%) & CaCO $_{3}(w t \%)$ \\
\hline 0.22 & 12.50 & 20.00 & 1.00 & 1.00 & 1.00 & 10.00 \\
\hline
\end{tabular}




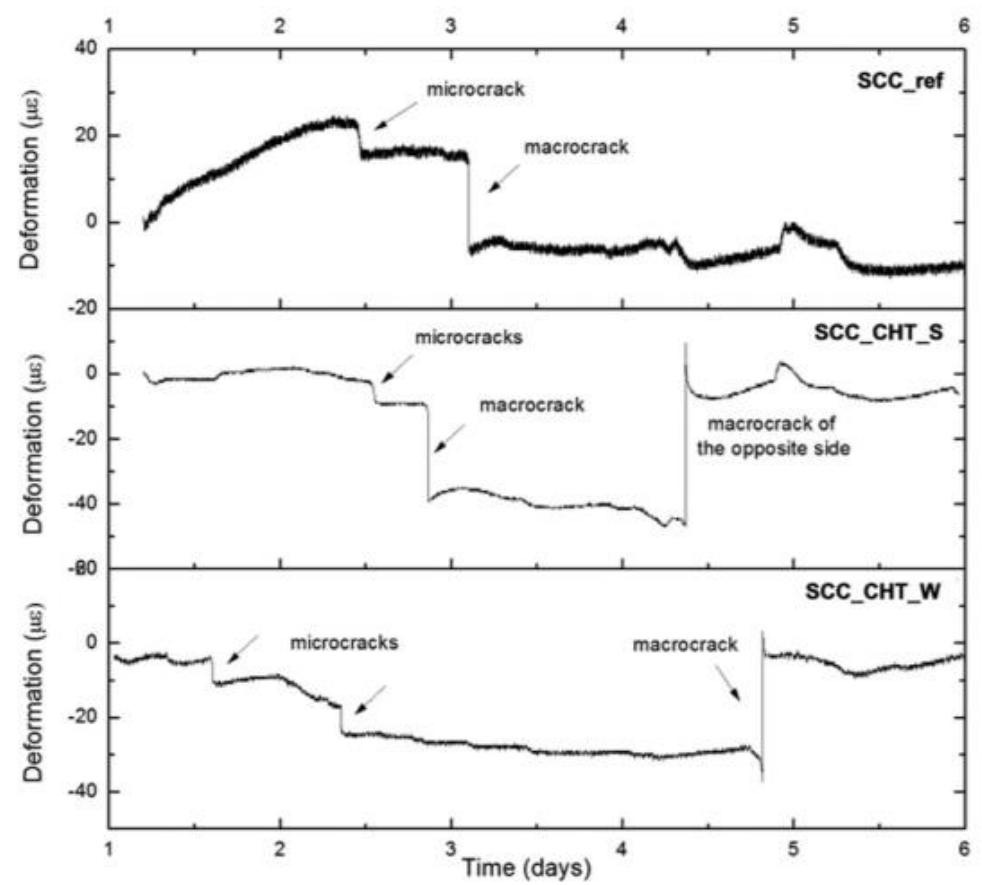

Figure 3. Ring tests results: plain concrete (SCC_ref); concrete with hollow tubes filled with sodium silicate solution (SCC_CHT_S); and concrete with hollow tubes filled with Rhodamine-colored water (SCC_CHT_W).

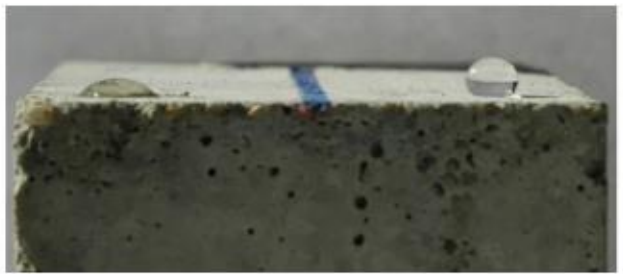

Figure 4. Water drops on a mortar sample: hydrophilic standard mortar surface (on the left side; contact angle roughly estimated to be about $45^{\circ}$ ) and hydrophobic mortar surface after treatment with a siloxanic hydrophobicizing agent in water solution (contact angle roughly estimated to be about $140^{\circ}$ ). 


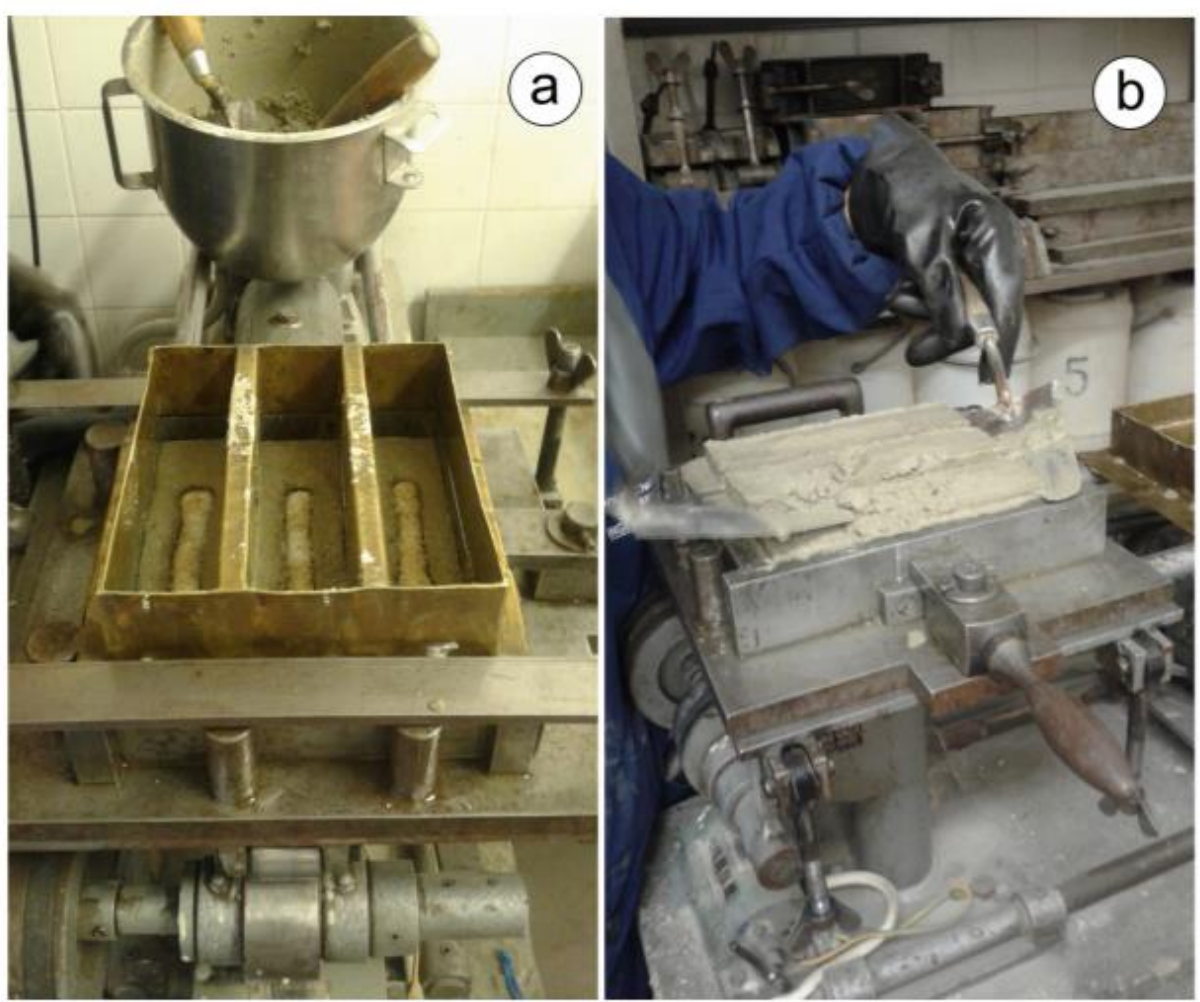

Figure 5. Two moments of the production of the self-healing mortar prisms with cementitious hollow tubes: (a) positioning of each tube approximately at the center of the specimen by laying it on the surface of a first layer of mortar poured in the mold and (b) completing the casting by removing the excess of mortar and finishing the surface of the sample.

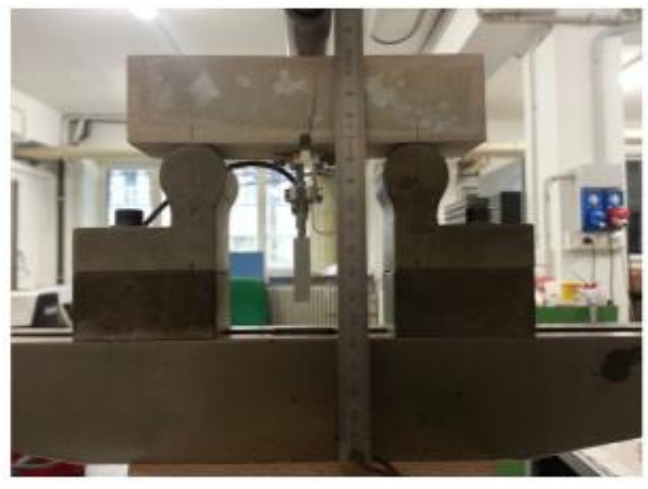

Figure 6. Specimen under load during the pre-loading stage with maximum CMOD of approximately $800 \mu \mathrm{m}$. 


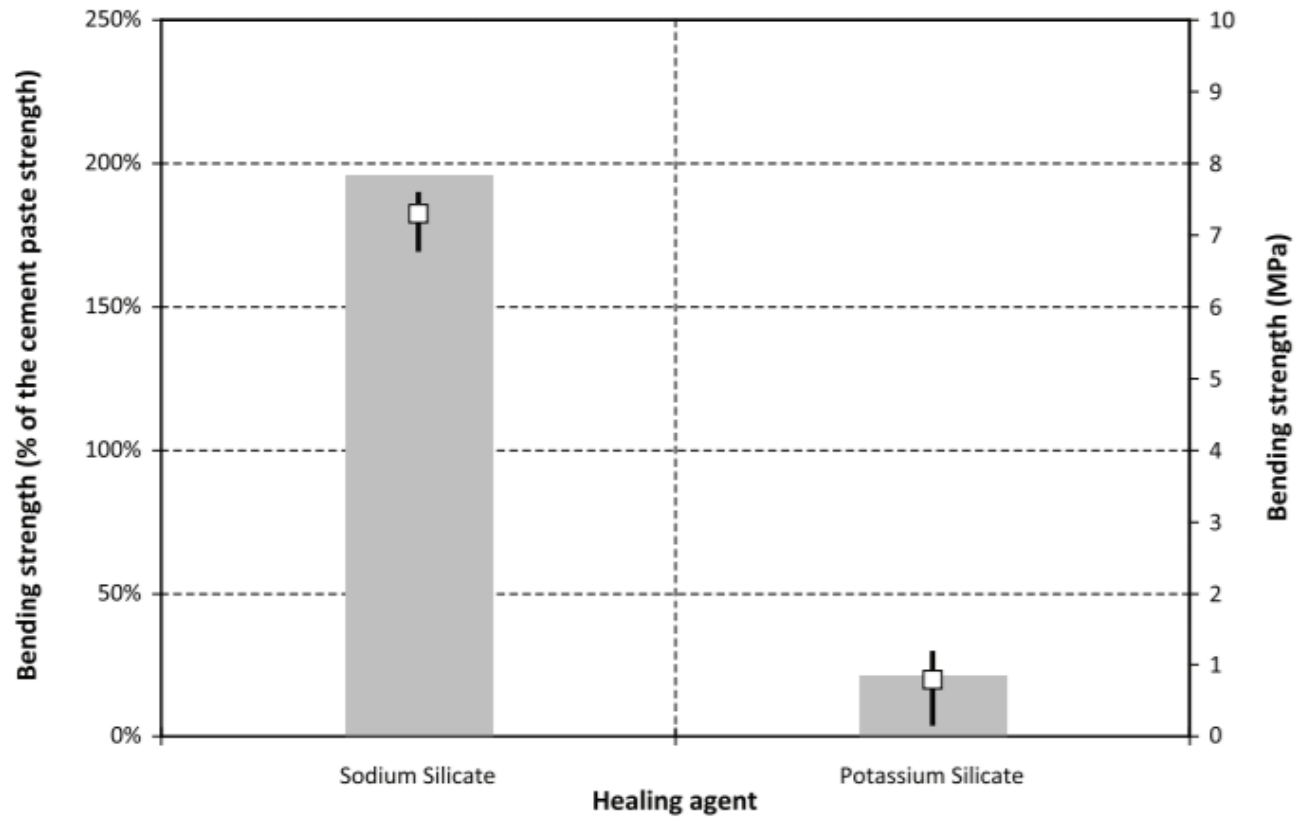

Figure 7. Preventive evaluation of sodium and potassium silicate as healing agents: white squares indicate the average bending strengths obtained on the samples reassembled using sodium or potassium silicate as a healing agent (values to be read on the right vertical axis); upper and lower edges of the solid black lines indicate, respectively, the maximum and the minimum values of the bending strengths obtained on the same samples (values to be read on the right vertical axis); gray bars indicate the average bending strengths obtained on the same samples as a percentage with respect to the initial cement paste strength (values to be read on the left vertical axis).

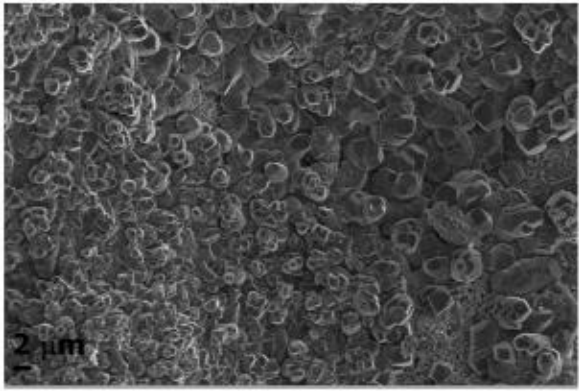

(a)

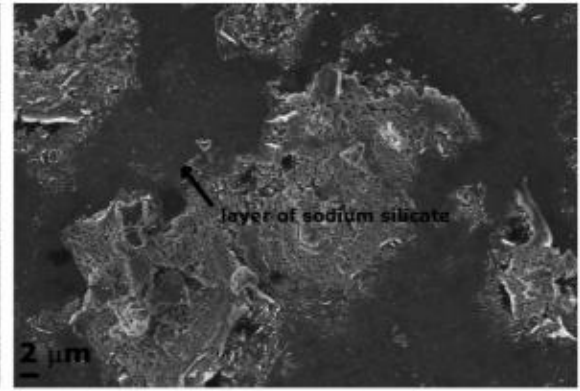

(b)

Figure 8. FE-SEM micrographs. (a) Inner surface of the extruded hollow tube without coating: the microstructure of the tube is clearly visible. (b) Inner surface of the hollow tube coated with the sodium silicate: the microstructure of the tube is covered by a homogeneous layer of coating.

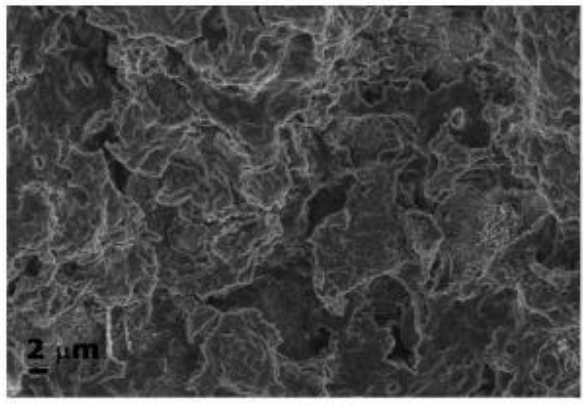

(a)

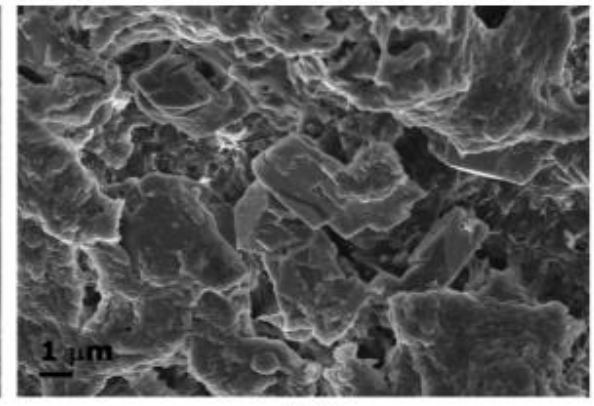

(b)

Figure 9. FE-SEM micrograph of hydrophobic coating settled on the inner surface of the extruded hollow tubes: (a) $\times 5000$ and (b) $\times 20,000$. The polymeric layer covers the microstructure of the cementitious paste. 


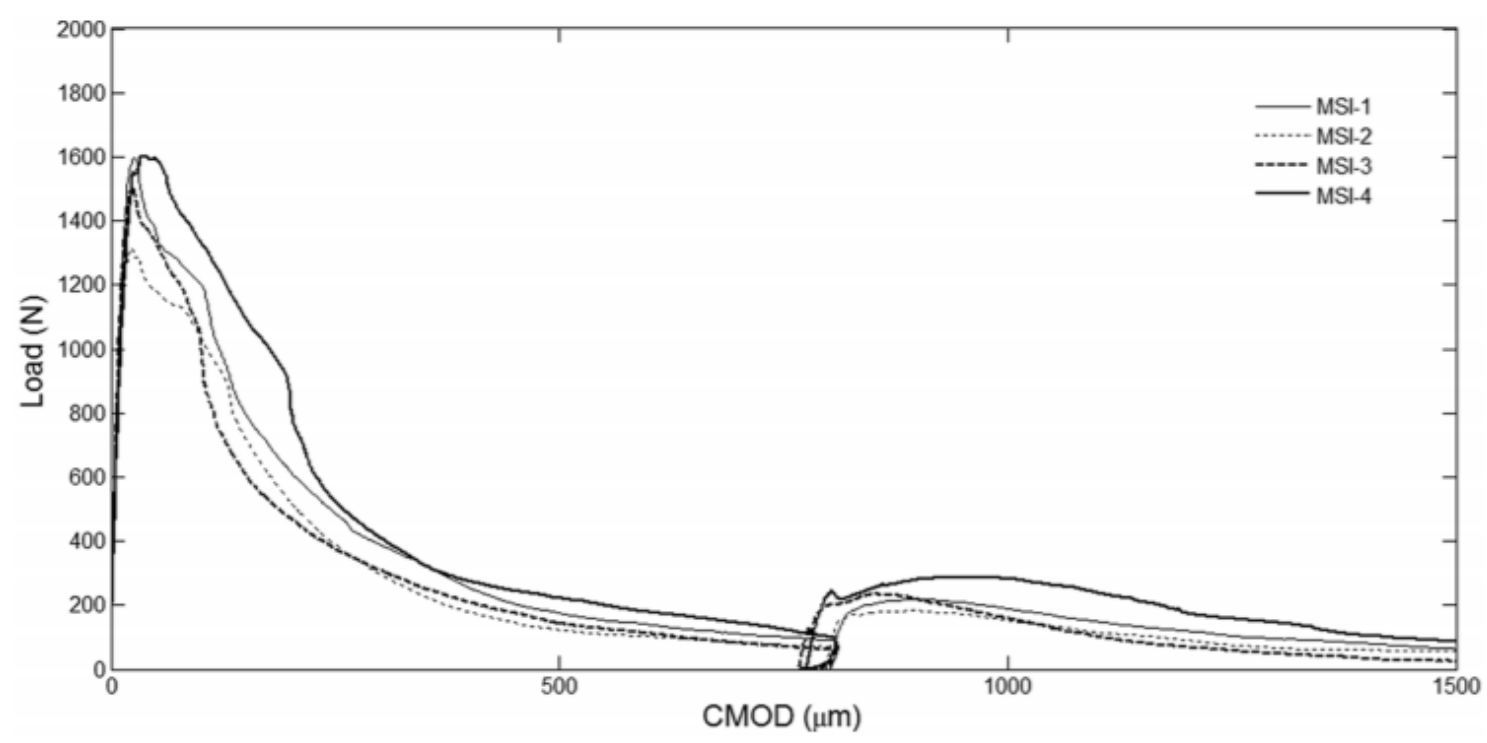

Figure 10. Load versus CMOD curves for self-healing specimens belonging to the MSI series, as resulting from pre-loading and re-loading stages.

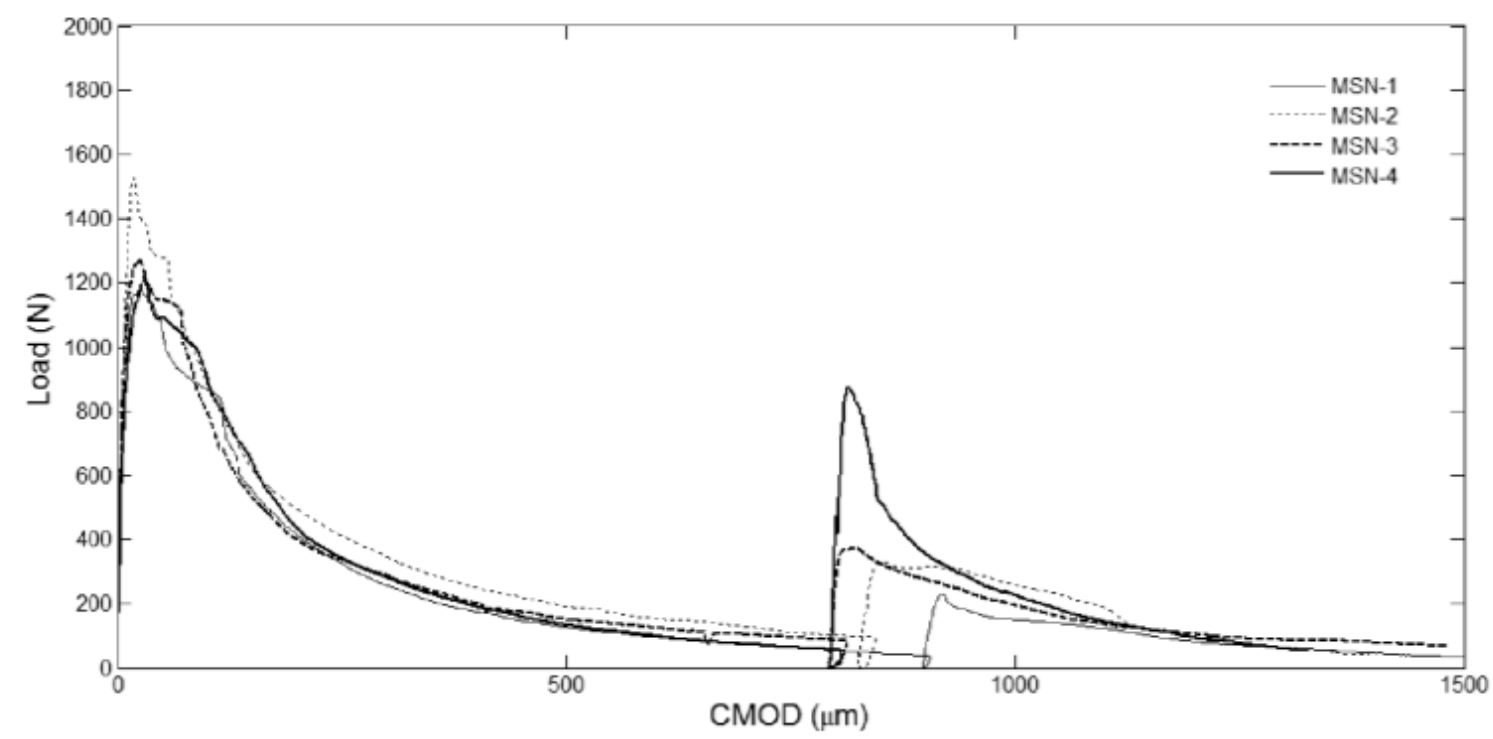

Figure II. Load versus CMOD curves for self-healing specimens belonging to the MSN series, as resulting from pre-loading and re-loading stages. 


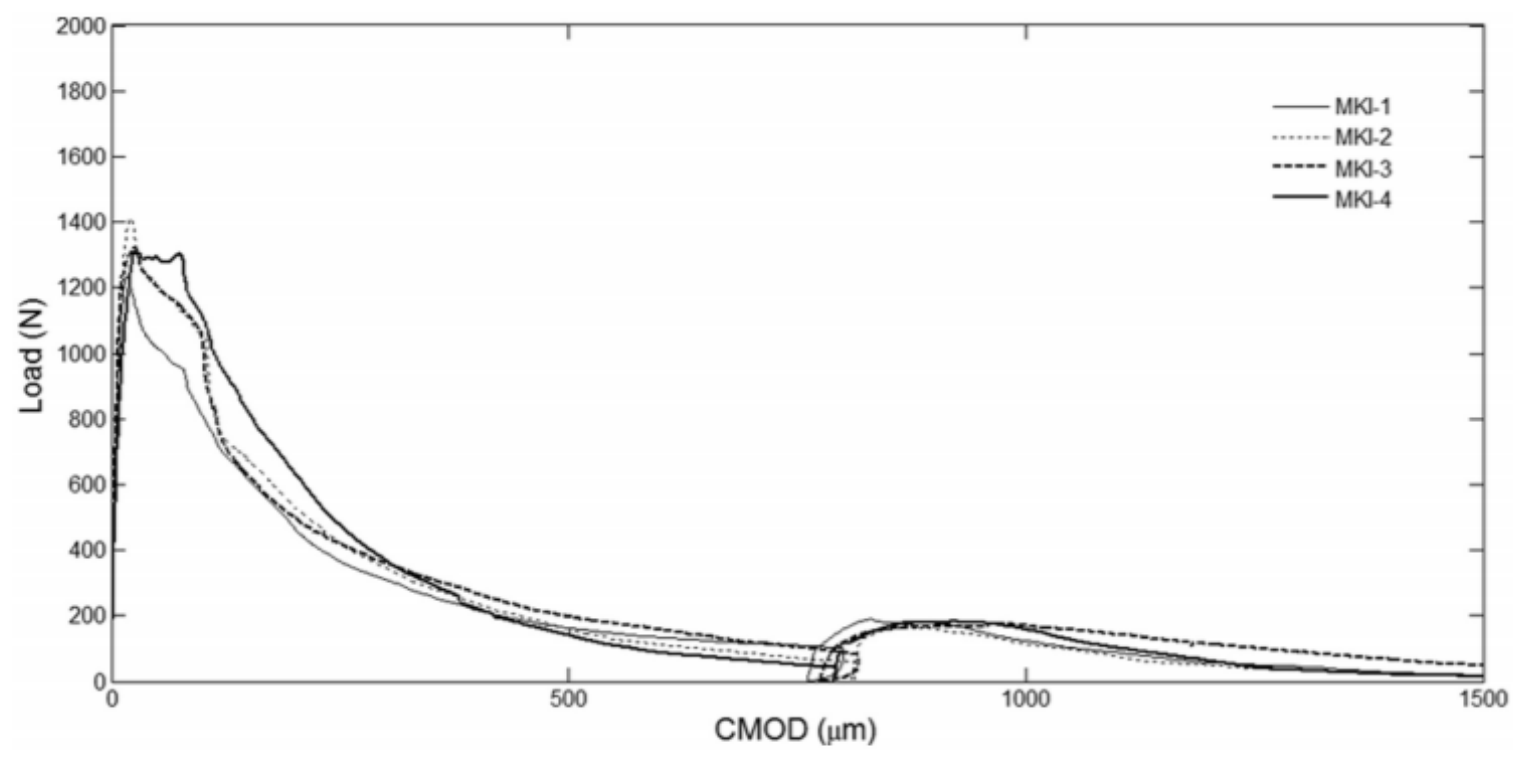

Figure 12. Load versus CMOD curves for self-healing specimens belonging to the MKI series, as resulting from pre-loading and re-loading stages.

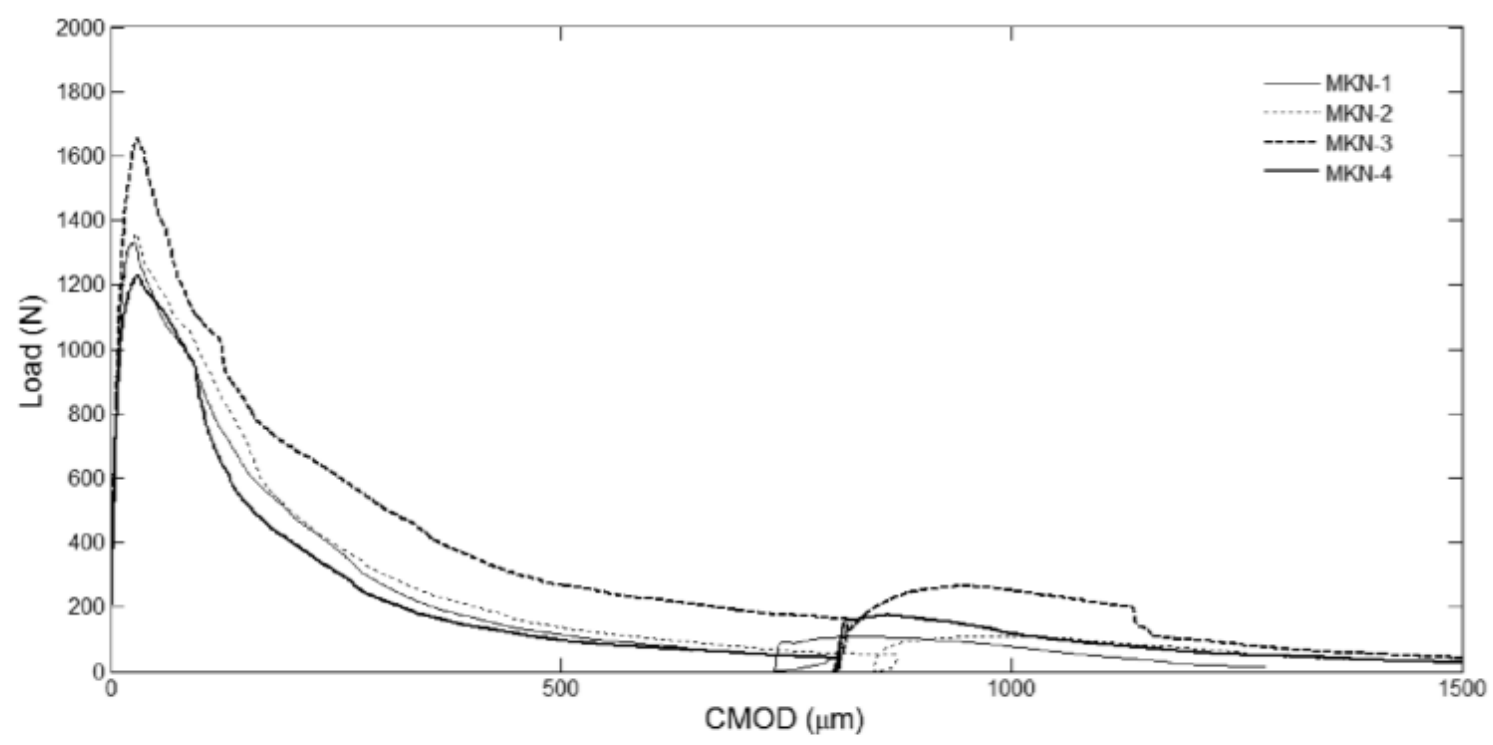

Figure 13. Load versus CMOD curves for self-healing specimens belonging to the MKN series, as resulting from pre-loading and re-loading stages. 


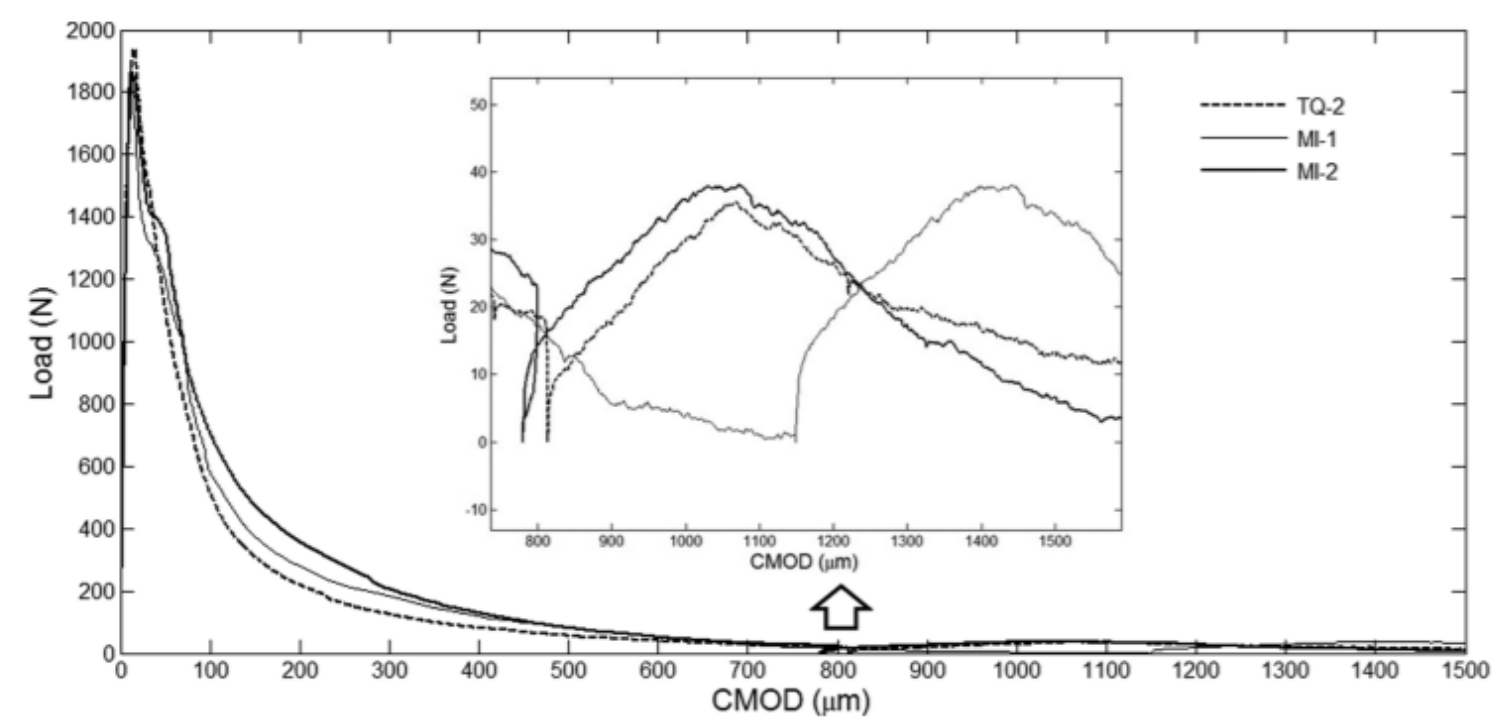

Figure 14. Load versus CMOD curves for reference specimens belonging to the TQ and MI series, as resulting from pre-loading and re-loading stages (data courtesy of Formia et al., 2015b). The inset reports a zoom on the un-loading/re-loading points.

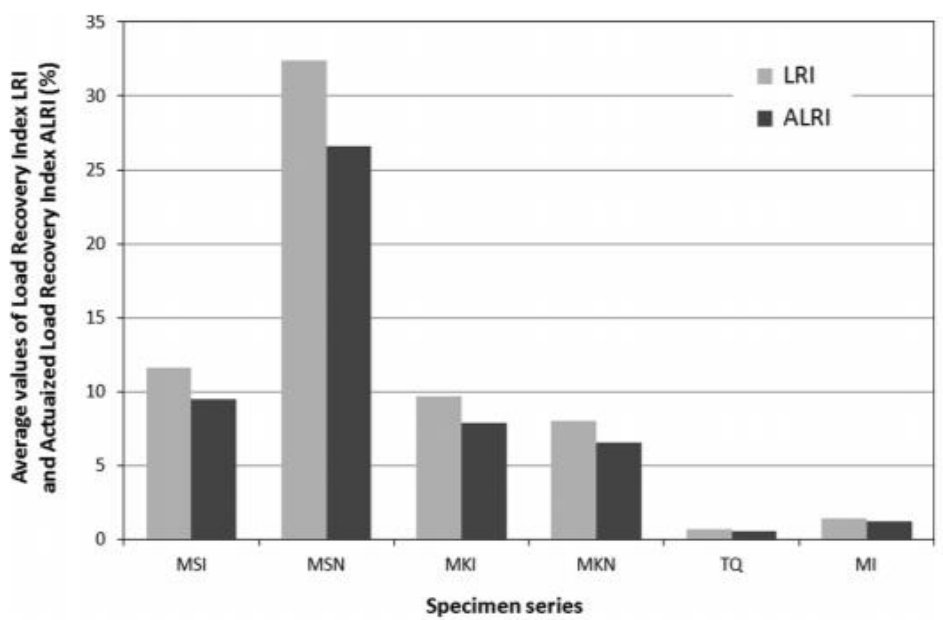

Figure 15. Average values of load recovery indices (light gray bars) and actualized load recovery indices (dark gray bars) for selfhealing mortar prisms (MSI, MSN, MKI, and MKN series) and for control specimens (TQ and MI series-courtesy of Formia et al., 2015b).

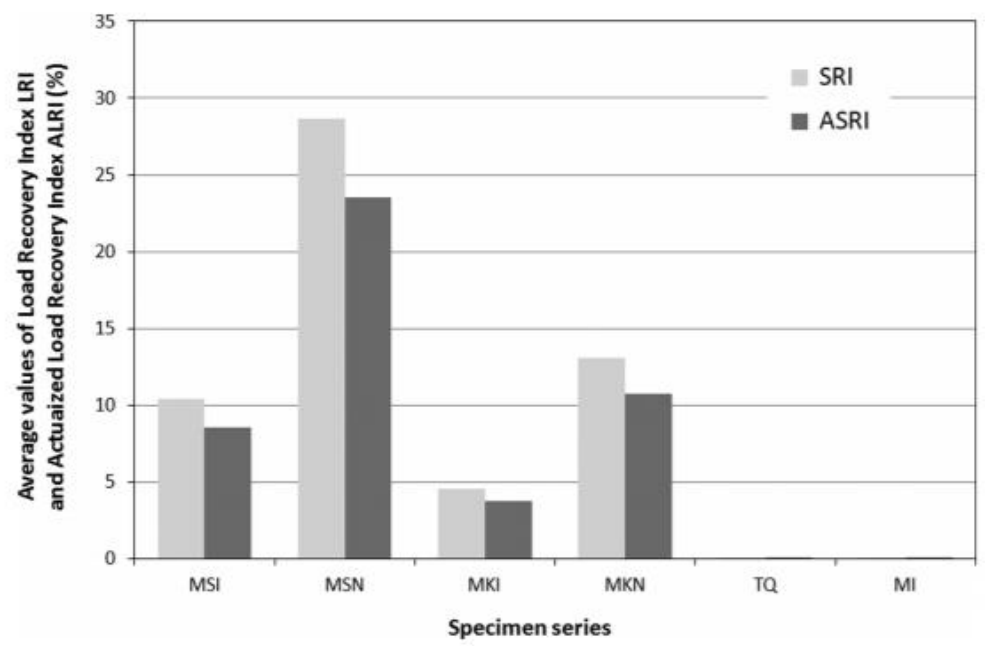

Figure 16. Average values of stiffness recovery indices (light gray bars) and actualized stiffness recovery indices (dark gray bars) for self-healing mortar prisms (MSI, MSN, MKI, and MKN series) and for control specimens (TQ and MI series-courtesy of Formia et al., 2015b). 
Table 4. Load and stiffness recovery indices, expansion area, distance of the tube with respect to the notch and aspect of the tube $(*)$ for some selected samples.

\begin{tabular}{|c|c|c|c|c|c|c|}
\hline Sample & $\begin{array}{l}\text { LRI } \\
\text { (ALRI) (\%) }\end{array}$ & $\begin{array}{l}\text { SRI } \\
\text { (ASRI) (\%) }\end{array}$ & $\begin{array}{l}\text { Expansion } \\
\text { area of } \\
\text { the healing } \\
\text { agent }\left(\mathrm{cm}^{2}\right)\end{array}$ & $\begin{array}{l}\text { Area respect } \\
\text { to the total } \\
\text { area }(\%)\end{array}$ & $\begin{array}{l}\text { Distance } \\
\text { between } \\
\text { the tube and } \\
\text { the notch }(\mathrm{cm})\end{array}$ & $\begin{array}{l}\text { Aspect } \\
\text { of the } \\
\text { tube }\left({ }^{\star}\right)\end{array}$ \\
\hline & $70.9(58.14)$ & $53.6(44.0)$ & 2.17 & 15.0 & 1.46 & 1.20 \\
\hline \multicolumn{7}{|l|}{$\mathrm{MSN}-4$} \\
\hline $\mathrm{MSN}-2$ & $17.2(14.1)$ & $15.7(12.9)$ & 1.07 & 7.4 & 1.45 & 1.15 \\
\hline $\mathrm{MSN}-3$ & $24.5(20.1)$ & $27.6(22.6)$ & 0.77 & 5.3 & 1.45 & 1.85 \\
\hline $\mathrm{MSI}-3$ & $12.3(10.1)$ & $6.3(5.2)$ & 2.05 & 14.2 & 1.55 & 1.42 \\
\hline MKN-2 & $5.3(4.3)$ & $2.7(2.2)$ & 0.27 & 1.9 & 1.73 & 1.20 \\
\hline MKI-2 & $8.8(7.2)$ & $10.6(8.7)$ & 2.16 & 15 & 1.45 & 1.4 \\
\hline MKI-I & $10.2(8.4)$ & $2.9(2.4)$ & 1.52 & 10.5 & 1.49 & 1.43 \\
\hline
\end{tabular}

Please note that the images present the samples with the notch downward, the same way as they were positioned in the loading frame of the testing for three-point bending tests. $\left({ }^{*}\right)$ The aspect of the tube is defined as the ratio between the major axis and the minor axis of an ellipse with the same area as the tube. 